\title{
Plastic zone size for nanoindentation of irradiated Fe-9\% Cr ODS
}

\author{
Corey K. Dolph ${ }^{1}$, Douglas J. da Silva ${ }^{1,2}$, Matthew J. Swenson ${ }^{1}$, and Janelle P. Wharry ${ }^{1,3^{*}}$
}

${ }^{1}$ Boise State University, 1910 University Drive, Boise, ID 83725, USA

${ }^{2}$ Federal University of São Carlos, Rodovia Washington Luís, km 235 - SP-310, São Carlos, São Paulo, Brazil

${ }^{3}$ Purdue University, 400 Central Drive, West Lafayette, IN 47907, USA

\begin{abstract}
The objective of this study is to determine irradiation effects on the nanoindentation plastic zone morphology in a model Fe-9\% Cr ODS alloy. Specimens are irradiated to 50 displacements per atom at $400^{\circ} \mathrm{C}$ with $\mathrm{Fe}^{++}$self-ions or to 3 dpa at $500^{\circ} \mathrm{C}$ with neutrons. The as-received specimen is also studied as a control. The nanoindentation plastic zone size is calculated using two approaches: (1) an analytical model based on the expanding spherical cavity analogy, and (2) finite element modeling (FEM). Plastic zones in all specimen conditions extend radially outward from the indenter, $4-5$ times the tip radius, indicative of fully plastic contact. Non-negligible plastic flow in the radial direction requires the experimentalist to consider the plastic zone morphology when nanoindenting ion-irradiated specimens; a single nanoindent may sample non-uniform irradiation damage, regardless of whether the indent is made top-down or in crosssection. Finally, true stress-strain curves are generated.
\end{abstract}

Keywords: oxide dispersion strengthened, nanoindentation, plasticity, ion irradiation 


\section{INTRODUCTION}

The growing use of charged particle irradiations to assess the integrity of advanced nuclear reactor candidate materials has increasingly called upon small-scale mechanical tests to assess irradiation effects on macroscopic mechanical properties. Amongst the many small-scale mechanical tests, nanoindentation is one of the most widely used [1]-[7]. Nanoindentation is simple, fast, and involves minimal sample preparation. In addition, nanoindentation techniques have been studied extensively for decades throughout the materials science community on thin films and layered materials [8]-[11]. As such, a robust understanding of the contact mechanics associated with nanoindentation has been developed [11]-[17]. However, several issues uniquely associated with irradiated specimens - and in particular, with ion-irradiated specimens - elicit further examination of the elasto-plastic response of irradiated materials to nanoindentation.

The challenges associated with conducting nanoindentation on irradiated specimens are well established [18]. First, ion irradiation produces a near-surface, inhomogeneous damage dose profile (Figure 1a). The depth of the damage profile can increase with increasing irradiating particle energy, or with decreasing particle mass. Similarly, lighter or more energetic irradiating ions produce damage profiles having a more extensive "flat" region on which the damage level is rather constant. Second, the indentation size effect [19]-[21] leads to overestimation of hardness for shallow indents typically $\leqslant 200 \mathrm{~nm}$. This observation is attributed to effects such as surface roughness and residual deformation from polishing. It is well known that materials having higher dislocation densities have a suppression of surface effects. Finally, another challenge with nanoindentation of ion irradiated materials is the combination of nearsurface oxidation and sputtering effects of the irradiation, together with ion implantation and 
chemical composition changes at the ion implantation peak. The net result of these effects, then, is a few hundred nm region between the surface and implantation peak, over which it is meaningful to probe nanohardness and obtain quantitative results.

But there remains the issue of the plastic zone sampled by a nanoindent. The development of a plastic zone, whose size increases during load application, is characteristic of indentation and nanoindentation experiments. The plastic zone is generally believed to be 5-10 times the depth of the indent for metals [17], [18], [22]-[24]. This would render top-down nanoindentation on an ion-irradiated surface rather impractical, as indents made deep enough so as to overcome surface effects may then oversample the softer, unirradiated bulk, while indents made shallow enough to sample the appropriate region in the damage profile will be overwhelmed by surface effects. Recent work [25]-[27] has successfully demonstrated topdown nanoindentation approaches on ion-irradiated materials that account for indentation size effects (i.e. surface effects), damage gradient effects, and softer substrate effects. But to simplify testing and analysis, studies have suggested utilizing nanoindentation on the cross-section (Figure 1b) [6], [7]. This approach, however, raises concerns about the radial extent of the plastic zone, which cannot be ignored.

It is therefore crucial to understand the extent of the plastic zone created by a nanoindent, in both the $z$-direction (below the indent) and radially. The shape of the plastic zone is indicative of the behavior of plastic flow: plastic zones confined below the indenter tip are indicative of elastically-dominated deformation, whereas plastic zones that extend radially outward from the indenter tip are indicative of fully-plastic contact [28], [29]. Quantifying the plastic zone size will also enable: (a) more accurate extraction of yield strength; (b) a continuum mechanics based examination of discrete deformation processes; and (c) assessment of the influence of the 
unirradiated "substrate" on the contact response of an ion-irradiated layer "thin film" (in the spirit of [8], [14]-[17], [30]-[32]).

We focus this study on a model oxide dispersion strengthened (ODS) alloy, which is a candidate material for structural and cladding components in advanced nuclear fission reactors and fusion first-wall applications. In ODS alloys, a fine dispersion of oxide nanoclusters act as defect sinks, limiting the growth of dislocation loops and voids within the matrix [33], [34]. But recently the stability of the nanoclusters has come into question, with some studies reporting stability [33], [35]-[40], others reporting ripening [41], [42], and yet others reporting dissolution [34], [43]-[46]. It has been shown that the irradiation evolution of the oxides has a significant impact on mechanical properties [47], and that critical analysis of nanoindentation studies can provide insight into the stability of the oxides [45].

The objective of this study is to determine the plastic zone generated by nanoindents in an irradiated model Fe-9\%Cr ODS alloy. We employ two parallel techniques. First, an analytical approach based upon the expanding spherical cavity model [28] provides an estimate of the plastic radii directly from nanoindentation experiments. Second, a finite element model provides a two-dimensional visualization of the plastic zone. Finally, cross-sectional transmission electron microscopy (TEM) through a nanoindent reveals a region of strain contrast below the indent, which is used to confirm analytical and finite element results. Together, these three approaches provide a comprehensive understanding of the plastic zone morphology. This work also demonstrates the effects of irradiation on the plastic zone, and calculates mechanical properties from nanoindentation results.

\section{METHODS}




\section{$\underline{2.1 \quad \text { Materials and irradiations }}$}

A model Fe-9\%Cr ODS alloy was obtained from the Japan Nuclear Cycle Development Institute (now known at the Japan Atomic Energy Agency). High purity powders of Fe, Cr, C, W, Ti, $\mathrm{Y}_{2} \mathrm{O}_{3}, \mathrm{Fe}_{2} \mathrm{Y}$, and $\mathrm{Fe}_{2} \mathrm{O}_{3}$ were ball milled in an attrition-type mill at 220 rpm for 48 hours under an Ar atmosphere. Milled powders were sealed in cans and degassed at $400^{\circ} \mathrm{C}$ and $0.1 \mathrm{~Pa}$, then hot extruded at $1200^{\circ} \mathrm{C}$ and forged into rods at $1150^{\circ} \mathrm{C}$. The final thermomechanical treatment involved a one hour anneal at $1050^{\circ} \mathrm{C}$ followed by air cooling to room temperature, then a one hour tempering at $800^{\circ} \mathrm{C}$ followed by air cooling to room temperature. The chemical composition of the alloy is provided in Table 1.

This study focuses on the as-received specimen and a specimen irradiated with $\mathrm{Fe}^{++}$selfions to 50 dpa at $400^{\circ} \mathrm{C}$. A specimen from the same Fe-9\% Cr ODS heat was also irradiated with neutrons to $3 \mathrm{dpa}$ at $500^{\circ} \mathrm{C}$, so its results are considered here as well.

For the ion irradiation, a $20 \mathrm{~mm} \times 2 \mathrm{~mm} \times 2 \mathrm{~mm}$ bar is cut from the bulk sample using electric discharge machining (EDM), then mechanically polished through 4000 grit silicon carbide paper. The residual damage layer is removed via electropolishing in a $10 \%$ perchloric acid $+90 \%$ methanol solution for 20 seconds at $-40^{\circ} \mathrm{C}$ and a potential of $35 \mathrm{~V}$. Irradiation with 5.0 $\mathrm{MeV} \mathrm{Fe}^{++}$ions is conducted with a raster-scanned beam at high vacuum $\left(<10^{-7}\right.$ torr $)$ using a 1.7 MV General Ionex Tandetron at the Michigan Ion Beam Laboratory. Rastering speed ensured that the irradiated region of the sample was covered every $3.92 \mathrm{~ms}$. The temperature is maintained at $399.3 \pm 4.4^{\circ} \mathrm{C}$, while the sample is irradiated at a dose rate of $\sim 10^{-4} \mathrm{dpa} / \mathrm{s}$. The irradiation damage profile (Figure 1a) is calculated using the "Quick Calculation” (KinchinPease) mode [48] in SRIM 2013 [49] and the displacements are obtained from the vacancy.txt 
file. The target irradiation dose of $50 \mathrm{dpa}$ is achieved at a depth of 500-600 nm from the surface, which avoids both the surface sink and the Fe implantation peak (Figure 1a).

Neutron irradiations are conducted in the Advanced Test Reactor (ATR) at Idaho National Laboratory (INL). The specimen is exposed to a fast neutron spectrum at a dose rate of $\sim 10^{-7} \mathrm{dpa} / \mathrm{s}$, until a total of $3 \mathrm{dpa}$ is accumulated. The irradiation temperature of $500 \pm 50^{\circ} \mathrm{C}$ is measured using melt wires. The specimen geometry is a $3 \mathrm{~mm}$ diameter transmission electron microscopy (TEM) disc with thickness $\sim 150-200 \mu \mathrm{m}$. Little to no neutron attenuation is experienced through these specimens [50], [51], resulting in a uniform damage profile throughthickness. Following irradiation, the specimen surface is prepared in a radioactive materials analysis laboratory at INL. The specimen is mechanically polished through 4000 grit $\mathrm{SiC}$ paper as needed, then electropolished in a $5 \%$ perchloric acid $+95 \%$ methanol solution at $-45^{\circ} \mathrm{C}$ for 5 seconds at $80 \mathrm{~V}$ and $70 \mathrm{~mA}$. Since the as-received material is also studied as a control, its surface is prepared in a manner consistent with the aforementioned technique.

\section{$\underline{2.2 \quad \text { Nanoindentation }}$}

Nanoindentation is performed at the Center for Advanced Energy Studies (CAES) using a Hysitron TI-950 Triboindenter. Indents are made using a high load transducer fitted with a Berkovich probe, which has a tip curvature $\sim 200 \mathrm{~nm}$. Indents are made in the top-down configuration, normal to the irradiated surface, using displacement-controlled mode to generate a depth profile of nanohardness. A series of indents is performed at depths ranging from 200 to $1000 \mathrm{~nm}$, at $100 \mathrm{~nm}$ intervals. Indent depths below $200 \mathrm{~nm}$ are avoided because the high load transducer is inaccurate at the low loads necessary to produce $<200 \mathrm{~nm}$ indents. A minimum of 13 indents are repeated at each depth to provide $>90 \%$ confidence in measurements. Indents are 
placed a minimum of $60 \mu \mathrm{m}$ apart to prevent plastic zone interactions and overlap. To reduce system creep, a three-segment loading curve is defined with a 20 second load period, 5 second hold period, and 20 second unload period.

Berkovich nanohardness and elastic moduli are calculated using the Oliver-Pharr method [52]. The yield strength is calculated using the relationship for b.c.c. Fe-Cr alloys [50]:

$$
\sigma_{y s}[\mathrm{MPa}]=3.06 \mathrm{H}_{V}\left[\mathrm{~kg} / \mathrm{mm}^{2}\right]
$$

where the Vickers hardness, $H_{V}$, in $\mathrm{kg} / \mathrm{mm}^{2}$, is directly related to the measured Berkovich nanohardness, $H_{B}$, in GPa using the relationship from Fischer-Cripps [53]:

$$
H_{V}\left[\mathrm{~kg} / \mathrm{mm}^{2}\right]=94.495 H_{B}[G P a]
$$

Although Eq. (2) was developed for microhardness measurements, it has been shown to be applicable to nanohardness, notably on an Fe-8Cr-2W ODS alloy [54].

Nanoindentation is highly sensitive to surface effects [19]. Surface roughness is measured for each specimen using the TI-950 TriboIndenter with a $1.00 \mathrm{~Hz}$ scan rate, $80 \mu \mathrm{m} / \mathrm{s}$ tip velocity, $0.5 \mu \mathrm{N}$ set point, and 240 integral gain. The as-received specimen has an average surface roughness of $58 \mathrm{~nm}$ with peak-to-valley height of $291 \mathrm{~nm}$. The neutron-irradiated specimen has a similar surface roughness, $52 \mathrm{~nm}$ with $244 \mathrm{~nm}$ peak-to-valley height. The ionirradiated specimen, however, has a considerably higher surface roughness of $\sim 100 \mathrm{~nm}$ with $\sim 400 \mathrm{~nm}$ peak-to-valley height, due to ion-induced surface sputtering during irradiation.

Because the ion irradiation damage layer is so shallow, we do not mechanically polish or flash electropolish the surface after irradiation, to prevent inadvertent removal of the irradiated layer. As such, the ion-irradiated specimen exhibits a higher surface roughness. However, since all indents are $\geq 200 \mathrm{~nm}$ (see previous paragraph), they are generally deep enough to overcome these surface roughness effects; implications of surface roughness will be discussed further in Sec 3.1. 


\section{$\underline{2.3 \quad \text { Microscopy }}$}

Focused ion beam (FIB) enables the lift-out of site-specific TEM lamellae and local electrode atom probe (LEAP) tomography needles [55]. The FEI Quanta 3D FEG FIB at CAES is used to extract a TEM lamella and a set of LEAP needles [55] from each specimen condition for microstructure characterization. Prior to milling, all specimen surfaces are protected with a platinum deposit to ensure that the original irradiated surface is retained for reference. TEM lamellae are oriented perpendicular to the irradiated surface, such that the ion irradiation damage profile is observed through the depth of the specimen. TEM lamellae are milled at $30 \mathrm{kV}$ to approximate dimensions of $15 \mu \mathrm{m} \times 7 \mu \mathrm{m} \times 100 \mathrm{~nm}$, followed by further milling at $5 \mathrm{kV}$ to a thickness of 50-100 nm. Finally, $2 \mathrm{kV}$ cleaning for approximately 1 minute on each side reduces surface damage to the sample caused by the prior milling steps. LEAP needles are fabricated in a similar manner, by first lifting a wedge oriented perpendicular to the irradiated surface. Wedges are mounted onto silicon posts and partitioned to produce 6-8 APT tips per specimen. The tips are then milled using annular ring patterns to shape them into needles with tip radius $\leq 50 \mathrm{~nm}$ [56]. The needles are sharpened such that the tip of each needle is positioned just below the original irradiated surface.

TEM specimens are analyzed using an FEI Tecnai TF30-FEG STwin STEM at CAES, which has a $0.19 \mathrm{~nm}$ point-to-point resolution. Dislocation loops are imaged using small collection and convergence angles to create a STEM bright field image [57]. Specimen thickness is measured with electron energy loss spectroscopy (EELS). LEAP needles are analyzed with a Cameca LEAP 4000X HR at CAES, operated in laser pulsed mode with samples held at $40 \mathrm{~K}$. Laser power ranges over $40-70 \mathrm{pJ}$ with a pulse repetition rate of $200 \mathrm{kHz}$. Each 
data set is reconstructed and analyzed with the Integrated Visualization and Analysis Software (IVAS) Version 3.6.2. Additional details about TEM and LEAP sample preparation and analysis are available in ref. [34].

TEM lamellae are also lifted from selected nanoindents in order to image the plastic zone below the indent in cross-section. FIB allows for precise location control [55] to ensure the center of the desired indent is contained within the TEM lamella. A protective platinum layer is deposited across the indent of interest, then the lift-out proceeds in the same manner as for conventional TEM lamellae described above.

Automated Crystal Orientation Mapping in the TEM (ACOM-TEM) [58] is performed using the NanoMEGAS ASTAR ${ }^{\mathrm{TM}}$ system to image the plastic zone in the TEM lamellae taken across nanoindents. ACOM-TEM has been used successfully to map the orientation gradient that illustrates the extent of plastic deformation in single crystals [59]. A spot size of 9, which is equivalent to a $5 \mathrm{~nm}$ diameter beam, an $89 \mathrm{~mm}$ camera length, and a $0.6^{\circ}$ precession angle, is used for imaging. Scans of 600 points in the $\mathrm{x}$-direction and 500 points in the $\mathrm{y}$-direction cover the plastic region in $50 \mathrm{~nm}$ steps. Diffraction patterns collected by the TEM CCD camera are compared against those created using indexed data for a $92 \% \mathrm{Fe}+8 \% \mathrm{Cr}$ alloy having space group 229, $\operatorname{Im} \overline{3} m$, provided in Pearson's Crystal Data. The lattice parameter is modified to 2.88 $\AA$, which is measured using a Bruker AXS D8 Discover x-ray diffractometer (XRD).

Each ACOM-TEM scan produces four maps: reliability, orientation, index, and virtual bright field. Each map has a specific purpose. The reliability map provides visual indication of agreement between the recorded diffraction patterns and the index patterns used in the ASTAR ${ }^{\mathrm{TM}}$ software to determine grain orientation. Regions that are white in color have a high degree of correlation, while black regions are associated with greater mismatch. Orientation maps depict 
the crystallographic orientation of each imaged grain. Index maps section the image according to crystal index, creating distinct boundary regions that help locate individual grains. Finally, virtual bright field maps recreate the bright field image responsible for the recorded diffraction patterns, but because the electron beam precession averages out dynamical effects, dislocation contrast is greatly reduced [58] as compared to conventional bright field imaging.

\subsection{Finite element modeling (FEM)}

The three-dimensional nanoindentation is modeled using an axisymmetric twodimensional finite element mesh built in ABAQUS ${ }^{\mathrm{TM}}$ 6.12-2. The Berkovich indenter is modeled as a sharp, rigid cone with $70.3^{\circ}$ half-included tip angle, which provides the same depth-to-area ratio as the Berkovich tip [8] while reducing computational time. Boundary conditions of 0 displacement are applied to the base and left-hand side (representing the centerline of the indenter). A 1000-node mesh is used under frictionless conditions. The mesh spacing is finest nearest the indent, with increasingly larger elements further away from the indent. A non-penetrating hard contact is assumed normal to the indent.

A single bulk specimen is modeled for the as-received and neutron-irradiated conditions. For the ion-irradiated condition, a $1.5 \mu \mathrm{m}$ thin film representing the irradiation damage layer, is built on an unirradiated substrate. Model input parameters for elastic modulus and yield strength are taken from nanoindentation experiments. Load is applied to the indent in $0.6 \mathrm{mN}$ increments over 50 seconds for each step.

\section{RESULTS \& DISCUSSION}




\subsection{Nanoindentation}

The as-received ODS exhibits nanohardness ranging between 4.37 and $4.99 \mathrm{GPa}$ (Figure

2, Table 2). These values are consistent with the $~ 4.5-5.0 \mathrm{GPa}$ nanohardness range for an $\mathrm{Fe}-8 \mathrm{Cr}$ ODS alloy reported by Hosemann et al. [54]. There is an apparent peak in nanohardness at a depth of $400 \mathrm{~nm}$, although this peak is not statistically significant outside the error bars and its cause is unknown. Neutron irradiation increases nanohardness uniformly over all indent depths, resulting in nanohardness values ranging 4.66-5.14 GPa, which represents a $\sim 110-130 \mathrm{MPa}$ increase in yield stress (Figure 2, Table 2). This amount of strengthening is approximately half that observed by Hosemann, et al. [54] on Fe-8Cr ODS following 9-13 dpa irradiation at 350$380^{\circ} \mathrm{C}$, which is reasonable given the higher neutron irradiation temperature $\left(500^{\circ} \mathrm{C}\right)$ of the specimen studied herein. The nanohardness of both the as-received and neutron irradiated conditions can be considered constant as a function of depth, within the error bars. While the indentation size effect normally causes nanohardness to decrease with increasing indent depth, the nanohardness has been shown to reach a plateau for indent depths $\gtrsim 200 \mathrm{~nm}$ for materials with as high a yield strength as ODS [54].

The ion-irradiated specimen exhibits average nanohardness values close to those of the as-received specimen for indent depths $\leq 500 \mathrm{~nm}$. The low nanohardness values measured at 200 and $300 \mathrm{~nm}$ are attributed to the high surface roughness of the ion-irradiated specimen. A consequence of the surface roughness being on approximately the same order as the indent depth, is that some indents are performed on sloped regions, with only a portion of the indenter tip making contact with the specimen. The controlling software overestimates the actual contact, thus requiring lower loads to reach the desired depth. Surface roughness effects are observed only in the ion-irradiated specimen because of its $\sim 100 \mathrm{~nm}$ surface roughness, and are not 
observed in the as-received or neutron-irradiated specimens, which have surface roughness $\sim 50$ $\mathrm{nm}$. For indent depths $>500 \mathrm{~nm}$, however, the ion-irradiated specimen exhibits $\sim 100 \mathrm{MPa}$ hardening compared to the as-received material (Figure 2, Table 2). This observation is consistent with the presence of the ion irradiation damage peak.

The irradiated layer is considered a thin film of thickness $t \sim 1.94 \mu \mathrm{m}$ on unirradiated substrate. Robertson [60] showed for ion-irradiated austenitic steels, the mechanical properties of the ion-irradiated layer can be isolated from those of the substrate if the indent depth is $<0.33 t$, or $\sim 650 \mathrm{~nm}$ for the ion-irradiated specimen considered here. This is consistent with the work of Kasada [25], [26] and Miyazawa [27], who use the inflection point in the squared hardness vs. inverse depth curve to identify a critical indent depth beyond which the softer substrate affects nanohardness measurements. They find the critical indent depth to range $\sim 200-500 \mathrm{~nm}$, with a tendency for the critical indent depth to increase for deeper irradiation damage layers and for harder materials. Given the material and irradiation conditions studied herein, a critical indent depth $\gtrsim 500 \mathrm{~nm}$ is not unreasonable for the present work. On the other hand, measured mechanical properties approach those of the substrate for indent depths $\geq 0.55 t$ [45], or $\sim 1070 \mathrm{~nm}$ for the ion-irradiated specimen considered here. Since shallower indents are affected by the surface, while deeper indents oversample the damage peak and softer substrate, indents made to depths $\sim 500-650 \mathrm{~nm}$ are considered most representative of the hardness of the ion irradiation. Measurement errors are largest at deepest indent depths, where the force required to produce the indent approaches the load limit of the equipment.

Careful examination of the load-displacement curves (representative curves shown in Figure 3) validates the selection of appropriate testing parameters and accuracy of results. The point at which the probe makes contact with the sample surface is set as displacement $=0 \mathrm{~nm}$. 
Upon contact, load increase with indentation depth indicates that the sample and probe are clean and properly mounted. An adequate hold period is confirmed by the absence of a negative displacement prior to unloading, and by the absence of a characteristic bow shape associated with thermal drift or creep effects during testing. A tail at the end of the unloading curve is observed when the surface prevents uniform contact between the indenter probe and the sample [61]. There are little to no indications of such surface effects in the specimens tested.

One indent is selected for further study from each specimen. A $400 \mathrm{~nm}$ indent from the as-received specimen and a $700 \mathrm{~nm}$ indent from the neutron-irradiated specimen are selected, as these indents have overcome surface effects. For the ion-irradiated specimen, a $600 \mathrm{~nm}$ indent is selected, enabling us to determine whether the apparent hardening at that indent depth is attributed to oversampling the irradiation damage peak. Due to material elasticity and pile-up, the final residual depth of the indent can differ from the target indentation depth. The final residual depth $h_{f}$, is determined using the Oliver-Pharr method [52] to describe the power law of the unloading curve:

$$
P=\alpha\left(h-h_{f}\right)^{m}
$$

where $h$ is the target indent depth, $\alpha$ is a material constant and $\mathrm{m}$ is a constant ranging between 1.2 and 1.6 depending on how well the material maintains the probe tip geometry after unloading. Values of $h_{f}$ are $448 \mathrm{~nm}, 615 \mathrm{~nm}$, and $518 \mathrm{~nm}$ for the as-received, ion-irradiated, and neutron-irradiated specimens, respectively. Yield stresses are 1.28 GPa, 1.40 GPa, and 1.44 GPa, and elastic moduli are $218 \mathrm{GPa}, 194 \mathrm{GPa}$, and $223 \mathrm{GPa}$, measured from the as-received, ion-irradiated, and neutron-irradiated indents, respectively. Additional material parameters from nanoindentation are provided in Table 3. 


\subsection{Analytical solution for plastic zone size}

Indentation mechanics have long been interpreted by drawing an analogy between indentation and the expansion of a spherical cavity in an infinite medium, Figure 4 [23], [62], [63]. This analogy relates the elastic-plastic mechanical properties of a material to contact parameters such as hardness and plastic zone size, by setting the contact radius $a_{S}$ of a spherical indenter equal to that of a conical indenter. It has been demonstrated, that this analogy remains valid for the more complex geometry of a Berkovich indenter [12]. The spherical geometry is defined by an expanding core radius $R$ and a developing plastic zone radius $c$, while the Berkovich geometry is defined by the penetration depth $h_{s}$ and the depth of the plastic zone directly beneath the indenter $z_{y s}$ (Figure 4). The elastic-plastic boundary is assumed to be an elastic compressible core [28], [63]. This model has been used successfully by Robertson, et al. [22] to predict plastic deformation in $100-250 \mathrm{~nm}$ nanoindents on ion-irradiated $316 \mathrm{LN}$ austenitic stainless steel.

The plastic zone size is normalized for varying indent depths by calculating the ratio $c / R$ or $z_{y s} / h_{s}$. A well-known expression for $c / R$, from [64], considers the yield strength $\sigma_{y s}$, and the elastic modulus $E$, both of which are determined from nanoindentation:

$$
\frac{c}{R}=\left(\frac{2 E}{3 \sigma_{y s}}\right)^{1 / 3}
$$

The normalized plastic radius $c / R$ is calculated to be $4.84,4.52$, and 4.69 for the as-received, ionirradiated, and neutron-irradiated specimens, respectively (Table 3). It should be noted that because this calculation is based on the assumption of an expanding spherical cavity, the plastic zone is also assumed spherical. 


\subsection{Finite element modeling}

A two-dimensional finite element model (FEM) provides additional confirmation of plastic zone measurements. The model is based on the elastic modulus and yield strength measured through nanoindentation. Comparison of the load displacement curves generated from FEM to those measured during nanoindentation offer insight to the accuracy of the model (representative curves shown in Figure 5). FEM results for the $400 \mathrm{~nm}, 600 \mathrm{~nm}$, and $700 \mathrm{~nm}$ indents in the as-received, ion-irradiated, and neutron-irradiated specimens, respectively (Figure 6), show that the plastic zone extends beyond the contact radius of the indenter, and along the specimen surface. This behavior is characteristic of plastically-dominated deformation. However, the plastic zone is not perfectly spherical, and extends deeper below the indent (parallel to indent direction) than along the specimen surface (perpendicular to indent direction).

The ion irradiation damage layer is modeled as a hard thin film on a softer substrate. The irradiated layer exhibits greater localized increases in yield stress than does the unirradiated substrate. A stress discontinuity occurs at the interface between the irradiated and unirradiated layers (Figure 6b). These observations are consistent with the findings of Kramer et al. [17], who demonstrated that thin films alter the onset of plastic deformation during nanoindentation. In addition, Chen, et al. [65] describe how the presence of a thin film, either harder or softer, induces spatial restraints that limit the geometrically necessary dislocation interactions, thereby locally increasing yield strength in the film.

Because of the geometry of the plastic zones, it is appropriate to calculate the normalized plastic zone as $z_{y s} / h_{s}$ in addition to $c / R$. Von Mises criteria are used to determine values of $z_{y s}$ to be $3.13 \mu \mathrm{m}$ for the as-received sample, $4.38 \mu \mathrm{m}$ for the ion-irradiated sample, and $3.76 \mu \mathrm{m}$ for the neutron-irradiated sample (Table 3). The contact radius $a_{s}$, is $1.12 \mu \mathrm{m}, 1.69 \mu \mathrm{m}$, and 1.91 
$\mu \mathrm{m}$, for as-received, ion-irradiated, and neutron-irradiated, respectively. The indent penetration depth $h_{s}$, and the contact radius $a_{s}$, are related according to [12]:

$$
h_{s}=R-1.217 a_{s}
$$

where, for conical indenters, $\theta=60.3^{\circ}$, and according to [12]:

$$
\frac{a_{s}}{R}=\frac{2 \tan \theta}{1+\tan ^{2} \theta}=0.635
$$

The resulting normalized plastic zone sizes in the $z$-axis are $7.84,7.25$, and 5.49 for asreceived, ion-irradiated, and neutron-irradiated, respectively (Table 3). This trend again demonstrates reduction in normalized plastic zone size with irradiation, which is attributed to irradiation-induced hardening. The normalized plastic zone size is within the expected range of 5-10 for metals [17], [18], [22]-[24].

Values of $z_{y s} / h_{s}$ from FEM are larger than $c / R$ from the spherical cavity approach, especially for the as-received and ion-irradiated specimens, suggesting that the plastic zone is elongated, extending further in the $z$-direction (below the indent) than in the radial directions (along the sample surface). The relatively small change in $z_{y s} / h_{s}$ and $c / R$ values with ion irradiation is consistent with the minimal change in nanohardness over all indent depths (shown in Figure 2). Neutron irradiation leads to a more pronounced decrease in $z_{y s} / h_{s}$ than in $c / R$, and as such, the neutron-irradiated $z_{y s} / h_{s}$ and $c / R$ values fall closer in magnitude (5.49 and 4.69, respectively). This suggests that the significant hardening effect of neutron irradiation leads to a more spherically-shaped plastic zone, with extensive plastic flow in the radial direction.

The shape of the plastic zone has the greatest impact on the efficacy of nanoindentation for shallow ion-irradiated layers. When indenting in the top-down configuration, depending on the irradiating ion and its energy, it may not be possible to select an indent depth that overcomes surface effects while its $z_{y s} / h_{s}$ value samples the desired depth of the damage profile. But when 
indenting in the cross-sectional configuration, one cannot ignore the radial extent of plastic flow; an indent will sample a region that extends $\sim 4-5$ times radially around the indenter tip. Our calculated $z_{y} / h_{s}$ and $c / R$ values suggest that, if one wishes to probe irradiation hardening only in the depths $\leq 600 \mathrm{~nm}$ (where microstructure is evaluated) for $5 \mathrm{MeV} \mathrm{Fe}^{++}$ion-irradiated specimens, the nanoindent depth must be $\$ 80 \mathrm{~nm}$ in the top-down configuration, or $\$ 40 \mathrm{~nm}$ in

cross-section. Clearly, such shallow indents will be overwhelmed by surface effects and provide inaccurate quantitative data. These indent depths can increase or decrease depending on the irradiating ion mass and energy, and one's tolerance for the extent of non-uniform irradiation damage levels being sampled in a single nanoindent.

\subsection{Plastic zone imaging}

TEM lamellae taken through the cross-section of a nanoindent and its plastic zone are used to verify results of the two models. The specimens are imaged two ways, first by ACOMTEM, then using conventional bright field imaging. Results of both techniques are presented and discussed here.

Reliability maps for the as-received and neutron-irradiated samples (Figure 7) indicate that the ACOM-TEM software accurately captures diffraction patterns. However, the reliability map from the ion-irradiated sample contains large regions of mismatch, attributed to the high defect density in the irradiated layer. Defect contrast in the irradiated layer prevents the ACOMTEM software from discerning diffraction patterns and crystallographic orientations in the irradiated region. Orientation maps (Figure 7) reveal a random grain orientation below each indent. This is not surprising, since indents are conducted at room temperature, so grain rotation is not expected to occur. In addition, there is no evidence of grain boundary sliding, which is 
also not surprising: the $200-300 \mathrm{~nm}$ grain size is large enough to accommodate plastic deformation, precluding the stress buildup required for low temperature grain boundary sliding. However, ACOM-TEM results do not visually demonstrate the extent of the plastic zone created by each indent.

Conventional bright field TEM images (Figure 8) reveal some dark contrast below each indent, which may partly be attributed to residual strain in the material and could be indicative of the extent of the plastic zone. The ACOM-TEM virtual bright field maps provide equivalent images with reduced defect contrast. But the residual strain contrast is difficult to discern through the high density of grain boundaries and dislocations present in the ODS alloy, even prior to irradiation. One could convince oneself that the TEM contrast is consistent with the predicted plastic zone dimensions from FEM and analytical approaches. But, quantitatively determining the plastic zone size of a polycrystalline engineering alloy through image analysis alone remains non-trivial if not impossible [66]. Rather, image analysis should be used merely as a confirmatory step, conducted in parallel with analytical solutions and FEM.

\subsection{Microstructure considerations on yield stress and plastic zone}

A combination of TEM and LEAP is used to characterize the microstructure of the $\mathrm{Fe}^{++}$ ion-irradiated specimen. The as-received and neutron-irradiated specimens are characterized using the same techniques, but results for these conditions have already been published [34], and are summarized in Table 4 for the reader's reference. In the ion-irradiated specimen, the average grain size is $0.28 \pm 0.10 \mu \mathrm{m}$, the average carbide size is $0.09 \pm 0.05 \mu \mathrm{m}$, and the dislocation line density is $20.4 \pm 8.8 \times 10^{14} \mathrm{~m}^{-2}$. These features are statistically unchanged from the as-received condition, and are consistent with the neutron-irradiated specimen. A sparse population of 
irradiation-induced voids (Figure 9) are observed in the ion irradiated specimen. Their average diameter is $7.5 \pm 2.7 \mathrm{~nm}$, slightly larger than those in the neutron-irradiated specimen; void number densities are similar in both ion- and neutron-irradiated specimens. Irradiation-induced dislocation loops are imaged in STEM mode [57] on the [011] zone axis. Loop orientation maps [67] are used to determine whether the loops reside on the $\{111\}$ or $\{001\}$ habit plane. Loops produced by self-ion irradiation (Figure 10) have average diameter $9.8 \pm 3.4 \mathrm{~nm}$ at a number density of $1.9 \pm 0.5 \times 10^{21} \mathrm{~m}^{-3}$ which is statistically invariant from the loop population in the neutron-irradiated specimen. Despite the difference in dose and temperature, the ion and neutron irradiations produce similar microstructures.

Bright field images of the oxide nanoclusters are obtained from regions of low dislocation contrast, allowing the z-contrast of the clusters to be more visibly prominent. A limitation of this technique, however, is that nanoclusters $\lesssim 2 \mathrm{~nm}$ in diameter are difficult to resolve [57]. Thus, atomic-resolution imaging in LEAP (Figure 11) complements the TEM analysis. Following ion irradiation, the oxide nanoclusters have average diameter $4.4 \pm 2.2 \mathrm{~nm}$ and number density $357 \times 10^{21} \mathrm{~m}^{-3}$. Similar to the neutron-irradiated results [34], these measurements suggest partial dissolution of oxide nanoclusters as a result of self-ion irradiation.

The irradiated microstructure (summarized in Table 4) alters the yield strength of the material, by changing the size and number density of obstacles to dislocation motion. The change in yield stress can be predicted from the microstructure using the dispersed barrier model [50]:

$$
\Delta \sigma_{y s, i} \propto \sqrt{N d}
$$

where $\Delta \sigma_{y s, i}$ represents the contribution to strengthening of microstructural feature $i, N$ is the number density of feature $i$, and $d$ is the average diameter of feature $i$. All yield strength 
contributions are then combined through the root-sum-square approach (Eq, 8), which has been shown to be more accurate than the linear sum approach (Eq. 9) for this ODS alloy [47]:

$$
\begin{gathered}
\text { Root-sum-square: } \Delta \sigma_{y s}=\sqrt{\sum_{i}\left(\Delta \sigma_{y s, i}\right)^{2}} \\
\text { Linear sum: } \Delta \sigma_{y s}=\sum_{i} \Delta \sigma_{y s, i}
\end{gathered}
$$

Using the methodology outlined in ref. [47] to estimate the relative strength of each barrier type (dislocation loops, voids, and oxide nanoclusters), the predicted total change in yield stress from the microstructure is slightly larger in the neutron-irradiated specimen than the ionirradiated specimen, $112 \mathrm{MPa}$ versus $78 \mathrm{MPa}$ (Table 4). This is consistent with nanoindentation results (Table 2), which shows consistent neutron irradiation hardening on the order of $~ 110-130$ $\mathrm{MPa}$ at all indent depths, and ion irradiation hardening on the order of $\sim 100 \mathrm{MPa}$ considering indents $>500 \mathrm{~nm}$. The larger neutron irradiation hardening is also consistent with its smaller normalized plastic zone (Table 3) than that of the ion-irradiated specimen.

\subsection{Strain hardening exponent}

The strain hardening exponent is calculated based upon the spherical cavity analogy for indentation [12]. The ability to determine strain hardening and other rheological properties such as yield stress and elastic modulus from this combined analytical and nanoindentation approach provides a powerful tool to recreate a true stress-strain curve without having to indent using multiple tip geometries (as in the approach described by Bucaille, et al. [13]). The strain hardening exponent $n$ is determined through Eq. 10, which relates experimental parameters to calculated parameters.

$$
\frac{H}{\sigma_{r}}=f\left[\left(\frac{2}{3}\right)\left(\frac{\epsilon_{y s}}{0.1}\right)^{n}+\Theta(n)+M(n)\left(\frac{z_{y s}+1.217 a_{s}}{a_{s} / 0.635}\right)^{P(n)}\right]
$$


The contact radius $a_{s}$ and plastic zone depth $z_{y s}$, are taken from the FEM and analytical approaches, while nanohardness $H$ and yield strain $\epsilon_{y s}$ are determined directly from nanoindentation experiments. The probe geometry projection factor $f$, is 1.101 for a Berkovich indenter [12]. The uniaxial stress $\sigma_{r}$, is defined using Tabor's relationship between indentation stress and hardness [68]:

$$
\sigma_{r}=\frac{H}{2.7}
$$

The terms $\Theta(n), M(n)$, and $P(n)$ are functions that depend on the strain hardening coefficient:

$$
\begin{gathered}
\Theta(n)=2.5968+\frac{0.5097}{n} \\
M(n)=-2.2778-\frac{0.5479}{n} \\
P(n)=-3.0615 n-0.005
\end{gathered}
$$

The strain hardening exponent is $0.243,0.270$, and 0.324 for the as-received, ionirradiated, and neutron-irradiated conditions, respectively. These results are consistent with strain hardening exponents calculated by Robertson, et al. [45] for irradiated ODS alloys based on nanoindentation experiments alone. Their as-received ODS had a yield stress of $1300 \mathrm{MPa}$ with $n=0.26$. Following Fe self-ion irradiation to $100 \mathrm{dpa}$ at $600^{\circ} \mathrm{C}$, their yield stress and strain hardening exponent increased to $1510 \mathrm{MPa}$ and 0.32 , respectively.

Final elasto-plastic curves are given by:

$$
\sigma=K \epsilon^{n}
$$

where the strength coefficient $\mathrm{K}(\mathrm{MPa})$ is:

$$
K=E^{n} \sigma_{y s}^{1-n}
$$

The curves are reconstructed (Figure 12) and illustrate how irradiation increases the yield strength and strain hardening exponent. The yield strength increase is attributed predominantly 
to the nucleation and growth of dislocation loops and voids under irradiation. The strain hardening exponent increase, however, is indicative of at least partial oxide nanocluster dissolution [45]. Particle dissolution and strain localization are concomitant effects [45]. Recently, it is believed that oxide nanoclusters become more coherent as their size decreases [47], [69]. During plastic deformation, then, the smaller, coherent oxides are more likely sheared by dislocations than bypassed via the Orowan mechanism, leaving little to no trace of dislocation loop debris (Orowan loops) surrounding the oxides [45]. Stresses associated with dislocation debris around larger, incoherent nanoclusters require mobile dislocations to cross-slip [70], resulting in limited self-work hardening. But when nanoclusters dissolve into smaller, more coherent phases, less cross-slip is necessary, resulting in larger dislocation pile-ups [45] and an increase in strain hardenability. Thus, through this mechanism, an increase in strain hardening exponent is consistent with oxide dissolution.

\section{CONCLUSIONS}

In this study, Fe-9\% Cr ODS is irradiated to 50 dpa at $400^{\circ} \mathrm{C}$ with $\mathrm{Fe}^{++}$self-ions or to 3 dpa at $500^{\circ} \mathrm{C}$ with neutrons. Nanoindentation to various depths is used to probe irradiation hardening. The normalized plastic zone size from nanoindentation is calculated analytically based upon the expanding spherical cavity model, and also using finite element modeling. TEM image analysis is used as a confirmatory step. We conclude that:

1) Both ion and neutron irradiation lead to the reduction of the normalized plastic zone size.

2) In the as-received and ion-irradiated specimens, the plastic zone has an elongated shape that extends further below the indent than radially, evidenced by values of $z_{y s} / h_{s}$ from 
FEM being larger than values of $c / R$ from the spherical cavity approach. Nevertheless, plastic flow in the radial direction is non-negligible, as $c / R \sim 4-5$.

3) Neutron irradiation leads to a considerable decrease in $z_{y s} / h_{s}$ but little decrease in $c / R$, and the neutron-irradiated $z_{y} / h_{s}$ and $c / R$ values end up close in magnitude. Thus, neutron irradiation hardening creates a more spherically-shaped plastic zone, with extensive plastic flow in the radial direction.

4) The plastic zone morphology must be considered when conducting nanoindentation on ion-irradiated specimens. Depending on the irradiating ion and its energy, a non-uniform level of irradiation damage will be sampled in a single nanoindent, especially when indented in cross-section because the plastic zone extends $\sim 4-5$ times radially around the indenter tip.

5) Both ion and neutron irradiations produce an increase in yield stress and strain hardening coefficient. Mechanisms for these results are consistent with irradiation-induced oxide nanocluster dissolution.

\section{ACKNOWLEDGEMENTS}

This research was supported by the US Nuclear Regulatory Commission Grants NRC-HQ-8414-G-0056 and NRC-38-08-955; the US DOE Office of Nuclear Energy under DOE Idaho Operations Office Contract DE-AC07-05ID14517, as part of the Nuclear Science User Facilities experiments 14-485, 14-486, and 15-540; and the Micron Foundation. The authors thank M.D. Gram and P.M. Anderson of the Ohio State University for the insightful discussions on nanoindentation and their generous assistance with FEM analysis. We also acknowledge the Brazilian Scientific Mobility Program for sponsorship of DJD, the staff at the Microscopy and 
Characterization Suite at CAES for their assistance with microscopy and nanoindentation, and the staff at the Michigan Ion Beam Laboratory for their assistance with ion irradiations. 
Table 1. Chemical composition of model Fe-9\% Cr ODS alloy.

\begin{tabular}{|l|c|c|c|c|c|c|c|c|c|c|c|c|c|c|}
\hline \multicolumn{10}{|c|}{ Chemical composition (wt\%, balance $\mathrm{Fe})$} & \multicolumn{2}{l|}{} \\
\hline $\mathrm{C}$ & $\mathrm{Si}$ & $\mathrm{Mn}$ & $\mathrm{P}$ & $\mathrm{S}$ & $\mathrm{Ni}$ & $\mathrm{Cr}$ & $\mathrm{W}$ & $\mathrm{Ti}$ & $\mathrm{Y}$ & $\mathrm{O}$ & $\mathrm{N}$ & $\mathrm{Ar}$ & $\mathrm{Y}_{2} \mathrm{O}_{3}$ & Ex. O \\
\hline 0.14 & 0.048 & 0.05 & $<0.005$ & 0.004 & 0.06 & 8.67 & 1.96 & 0.23 & 0.27 & 0.14 & 0.017 & 0.004 & 0.34 & 0.07 \\
\hline$\left[\mathrm{Y}_{2} \mathrm{O}_{3}\right]=1.27 \times[\mathrm{Y}]$ \\
\hline
\end{tabular}


Table 2. Summary of nanohardness measurements; strengthening is calculated by taking the difference in hardness at the given depth and applying Eqs. (1) and (2).

\begin{tabular}{|c|c|c|c|c|c|}
\hline \multirow[b]{2}{*}{$\begin{array}{l}\text { Indent } \\
\text { Depth } \\
(\mathrm{nm})\end{array}$} & \multirow{2}{*}{$\begin{array}{c}\text { As-Received } \\
\text { Average } \\
\text { Berkovich } \\
\text { Hardness (GPa) }\end{array}$} & \multicolumn{2}{|c|}{ Ion-Irradiated } & \multicolumn{2}{|c|}{ Neutron-Irradiated } \\
\hline & & $\begin{array}{c}\text { Average } \\
\text { Berkovich } \\
\text { Hardness (GPa) }\end{array}$ & $\begin{array}{l}\text { Strengthening } \\
\quad(\mathrm{MPa})\end{array}$ & $\begin{array}{c}\text { Average } \\
\text { Berkovich } \\
\text { Hardness }(\mathrm{GPa})\end{array}$ & $\begin{array}{l}\text { Strengthening } \\
(\mathrm{MPa})\end{array}$ \\
\hline 200 & 4.37 & 4.26 & -32 & 4.66 & 84 \\
\hline 300 & 4.43 & 4.31 & -35 & 5.00 & 165 \\
\hline 400 & 4.99 & 4.70 & -84 & 4.67 & -93 \\
\hline 500 & 4.43 & 4.46 & 9 & 4.84 & 119 \\
\hline 600 & 4.44 & 4.83 & 113 & 4.90 & 133 \\
\hline 700 & 4.60 & 4.89 & 84 & 4.97 & 107 \\
\hline 800 & 4.50 & 5.00 & 145 & 5.02 & 150 \\
\hline 900 & 4.88 & 5.19 & 90 & 5.14 & 75 \\
\hline 1000 & 4.61 & 4.90 & 84 & 4.96 & 101 \\
\hline
\end{tabular}


Table 3. Calculation of normalized plastic zone size and strain hardening coefficient.

\begin{tabular}{|c|c|c|c|c|}
\hline Parameter & Variable & $\begin{array}{c}\text { As- } \\
\text { Received }\end{array}$ & $\begin{array}{c}\text { Ion- } \\
\text { Irradiated }\end{array}$ & $\begin{array}{l}\text { Neutron- } \\
\text { Irradiated }\end{array}$ \\
\hline Target indent depth (nm) & $h$ & 400 & 600 & 700 \\
\hline Final indent depth $(\mathrm{nm})$ & $h_{f}$ & 448 & 615 & 518 \\
\hline \multicolumn{5}{|c|}{ Nanoindentation measurement } \\
\hline Berkovich Hardness (GPa) & $H_{B}$ & 4.43 & 4.83 & 4.97 \\
\hline Yield strength $(\mathrm{GPa})$ & $\sigma_{y s}$ & 1.28 & 1.40 & 1.44 \\
\hline Yield strain (\%) & $\epsilon_{\mathrm{ys}}$ & 0.0058 & 0.0072 & 0.0064 \\
\hline Elastic modulus (GPa) & $E$ & 218 & 194 & 223 \\
\hline \multicolumn{5}{|c|}{ Analytical calculation } \\
\hline Applied load (mN) & $P$ & 29.0 & 55.5 & 46.7 \\
\hline Contact radius $(\mu \mathrm{m})$ & $a_{s}$ & 1.47 & 2.16 & 1.95 \\
\hline Normalized plastic zone size & $c / R$ & 4.84 & 4.52 & 4.69 \\
\hline \multicolumn{5}{|c|}{ Finite element model } \\
\hline Final indent depth $(\mathrm{nm})$ & $h_{f}$ & 400 & 600 & 700 \\
\hline Plastic zone size directly below indent $(\mu \mathrm{m})$ & $z_{y s}$ & 3.13 & 4.38 & 3.76 \\
\hline Applied load $(\mathrm{mN})$ & $P$ & 16.2 & 38.2 & 63.0 \\
\hline Contact radius $(\mu \mathrm{m})$ & $a_{s}$ & 1.12 & 1.69 & 1.91 \\
\hline Penetration depth $(\mathrm{nm})$ & $h_{s}$ & 399 & 604 & 685 \\
\hline Normalized plastic zone size in the $z$-axis & $z_{y s} / h_{s}$ & 7.84 & 7.25 & 5.49 \\
\hline \multicolumn{5}{|c|}{ Strain hardening coefficient calculation } \\
\hline Uniaxial stress (MPa) & $\sigma_{r}$ & 1640 & 1790 & 1840 \\
\hline Strain hardening coefficient & $n$ & 0.243 & 0.270 & 0.324 \\
\hline
\end{tabular}


Table 4. Summary of microstructural measurements using TEM; as-received and neutron irradiated data from Ref. [34].

\begin{tabular}{|c|c|c|c|c|}
\hline Feature & Measurement & As-received & $\begin{array}{l}\mathrm{Fe}^{++} \text {irradiated } \\
\left(50 \mathrm{dpa}, 400^{\circ} \mathrm{C}\right)\end{array}$ & $\begin{array}{c}\text { Neutron-irradiated } \\
\left(3 \mathrm{dpa}, \mathbf{5 0 0}^{\circ} \mathrm{C}\right)\end{array}$ \\
\hline \multirow{2}{*}{ Grains/Laths } & \# of grains measured & 104 & 105 & 104 \\
\hline & Effective diameter $\left(\mathrm{x} 10^{-6} \mathrm{~m}\right)$ & $0.23 \pm 0.12$ & $0.28 \pm 0.10$ & $0.31 \pm 0.09$ \\
\hline \multirow{2}{*}{$\begin{array}{c}\text { Dislocation } \\
\text { lines }\end{array}$} & \# of measurements & 17 & 27 & 39 \\
\hline & Density (x 10 $\left.10^{14} \mathrm{~m}^{-2}\right)$ & $19.1 \pm 3.8$ & $20.4 \pm 8.8$ & $18.5 \pm 4.8$ \\
\hline \multirow{3}{*}{$\begin{array}{c}\text { Carbide } \\
\text { Precipitates }\end{array}$} & $\#$ of carbides measured & 36 & 45 & 68 \\
\hline & Effective diameter $\left(\mathrm{x} 10^{-6} \mathrm{~m}\right)$ & $0.11 \pm 0.07$ & $0.09 \pm 0.05$ & $0.10 \pm 0.06$ \\
\hline & Density $\left(\mathrm{x} 10^{20} \mathrm{~m}^{-3}\right)$ & 0.20 & 0.17 & 0.47 \\
\hline \multirow{3}{*}{ Voids } & \# of voids measured & 0 & 63 & 22 \\
\hline & Diameter $\left(\times 10^{-9} \mathrm{~m}\right)$ & - & $7.5 \pm 2.7$ & $3.6 \pm 1.1$ \\
\hline & Density $\left(\mathrm{x} 10^{21} \mathrm{~m}^{-3}\right)$ & - & $0.5 \pm 0.2$ & $0.2 \pm 0.1$ \\
\hline \multirow{3}{*}{$\begin{array}{l}\text { Dislocation } \\
\quad \text { loops }\end{array}$} & \# of loops measured & 0 & 81 & 182 \\
\hline & Diameter $\left(\times 10^{-9} \mathrm{~m}\right)$ & - & $9.8 \pm 3.4$ & $8.9 \pm 2.0$ \\
\hline & Density $\left(\mathrm{x} 10^{21} \mathrm{~m}^{-3}\right)$ & - & $1.9 \pm 0.5$ & $2.3 \pm 0.7$ \\
\hline \multirow{3}{*}{$\begin{array}{c}\text { Oxide } \\
\text { nanoclusters }\end{array}$} & \# of nanoclusters measured & 486 & 93 & 335 \\
\hline & Diameter $\left(\right.$ x $\left.10^{-9} \mathrm{~m}\right)$ & $5.96 \pm 3.10$ & $4.38 \pm 2.22$ & $3.41 \pm 1.69$ \\
\hline & Density $\left(\mathrm{x} 10^{21} \mathrm{~m}^{-3}\right)$ & 568 & 357 & 435 \\
\hline \multicolumn{2}{|c|}{$\Delta \sigma_{\mathrm{ys}}$ calculated from microstructure } & - & 78 & 112 \\
\hline \multicolumn{2}{|c|}{$\Delta \sigma_{\mathrm{ys}}$ measured by nanoindentation } & - & $\sim 100$ & $\sim 110-130$ \\
\hline
\end{tabular}




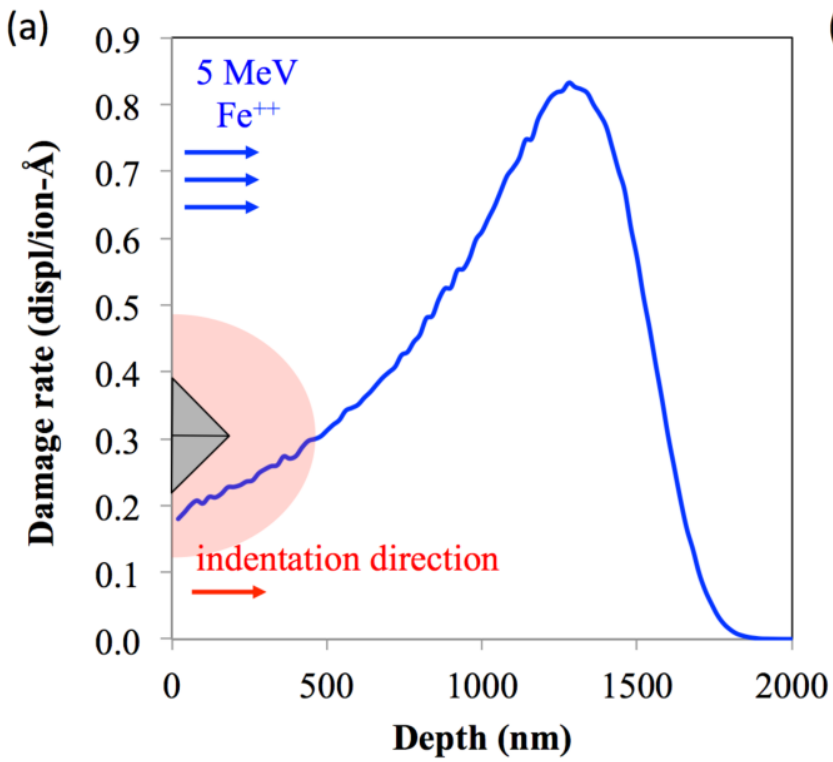

(b)

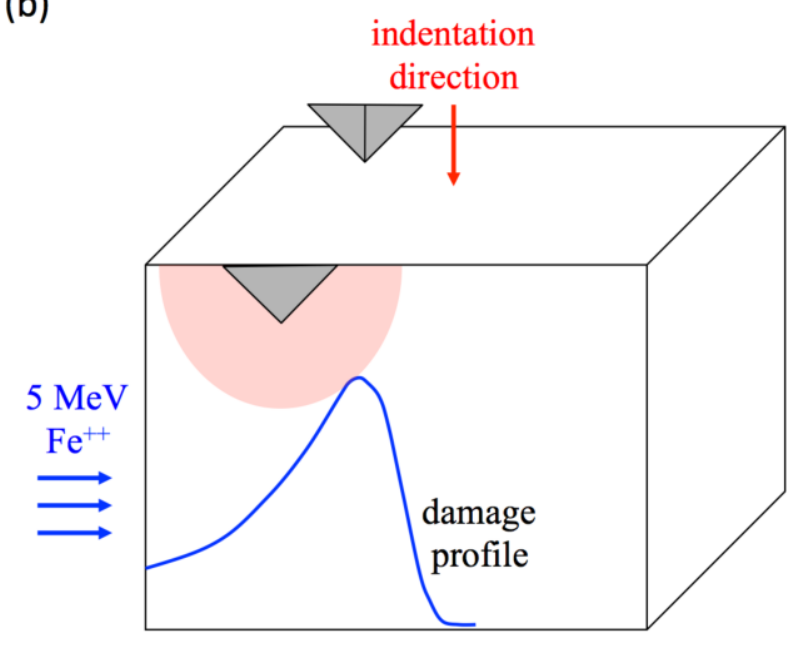

Figure 1. (a) Damage profile for $5 \mathrm{MeV} \mathrm{Fe}^{++}$on Fe-9Cr ODS calculated from SRIM, overlaid with schematic of top-down nanoindentation with plastic zone, indentation direction is parallel to irradiation direction. (b) Schematic of cross-sectional nanoindentation with plastic zone, showing indentation direction perpendicular to irradiation direction. 


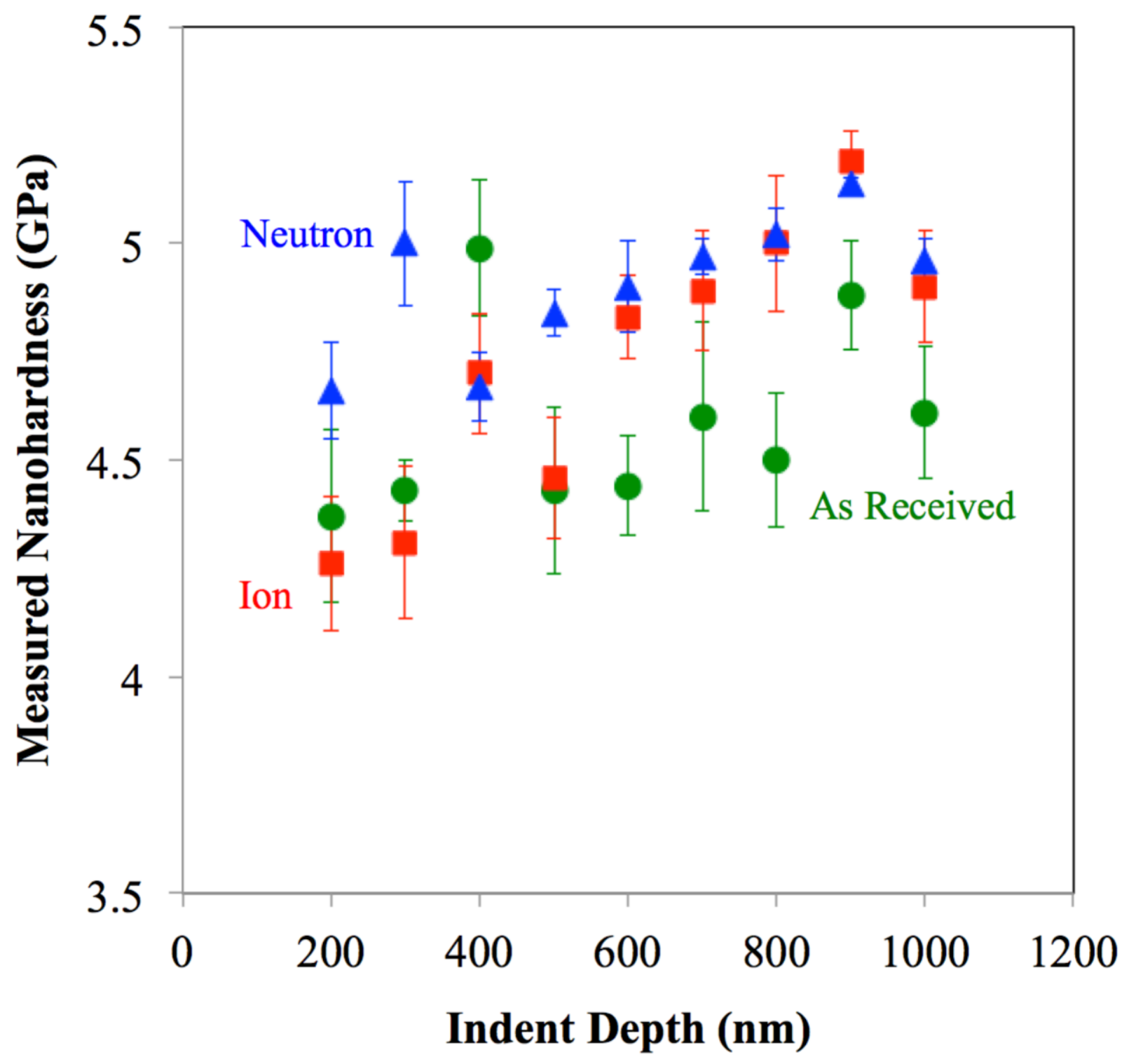

Figure 2. Average nanohardness as a function of indent depth for as-received (green circles), ion-irradiated (red squares), and neutron-irradiated (blue triangles) specimens. 


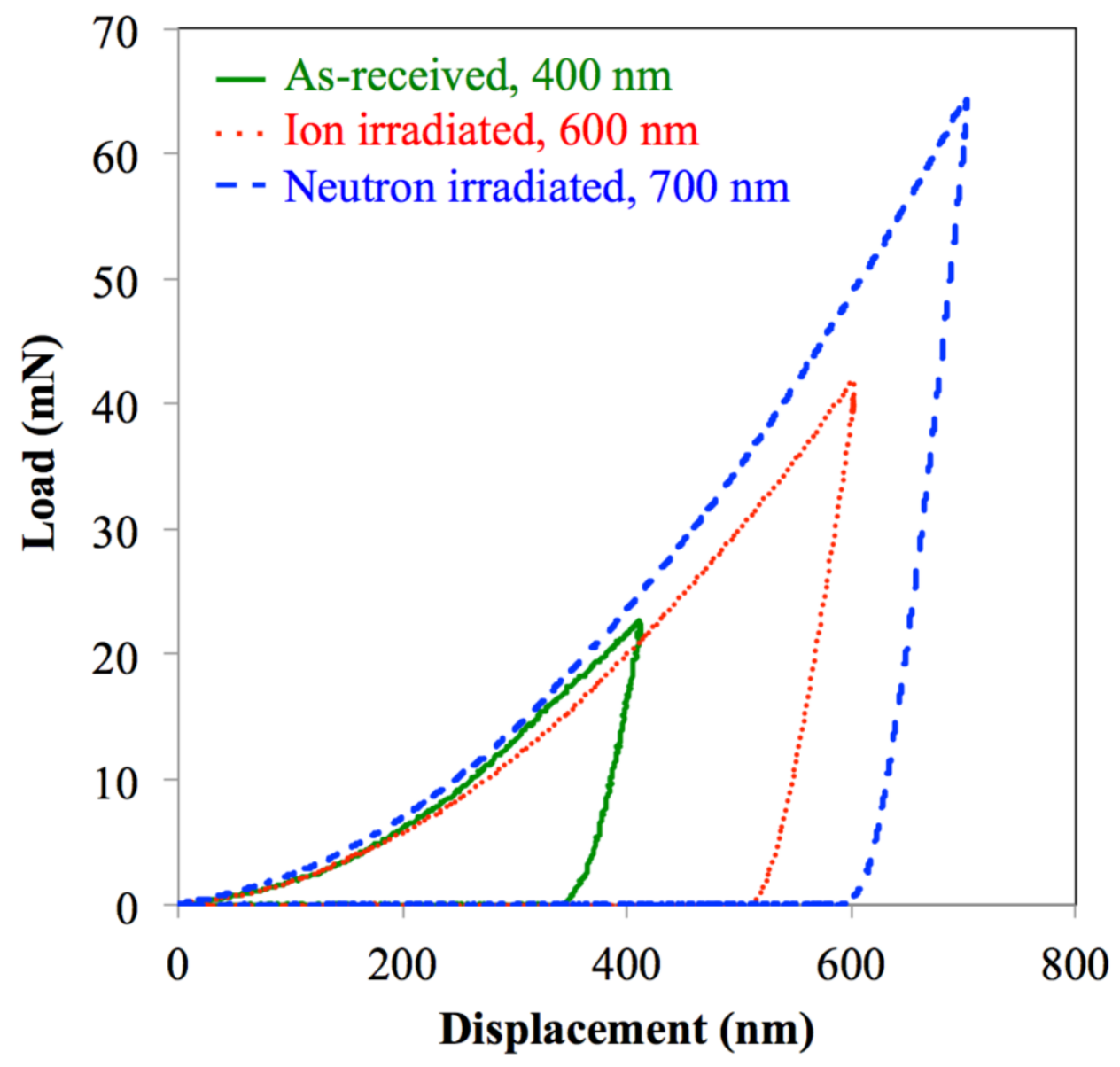

Figure 3. Representative load-displacement curves from nanoindentation for $400 \mathrm{~nm}$ indent on the as-received material, $600 \mathrm{~nm}$ indent on the ion-irradiated material, and $700 \mathrm{~nm}$ indent on the neutron-irradiated material. 


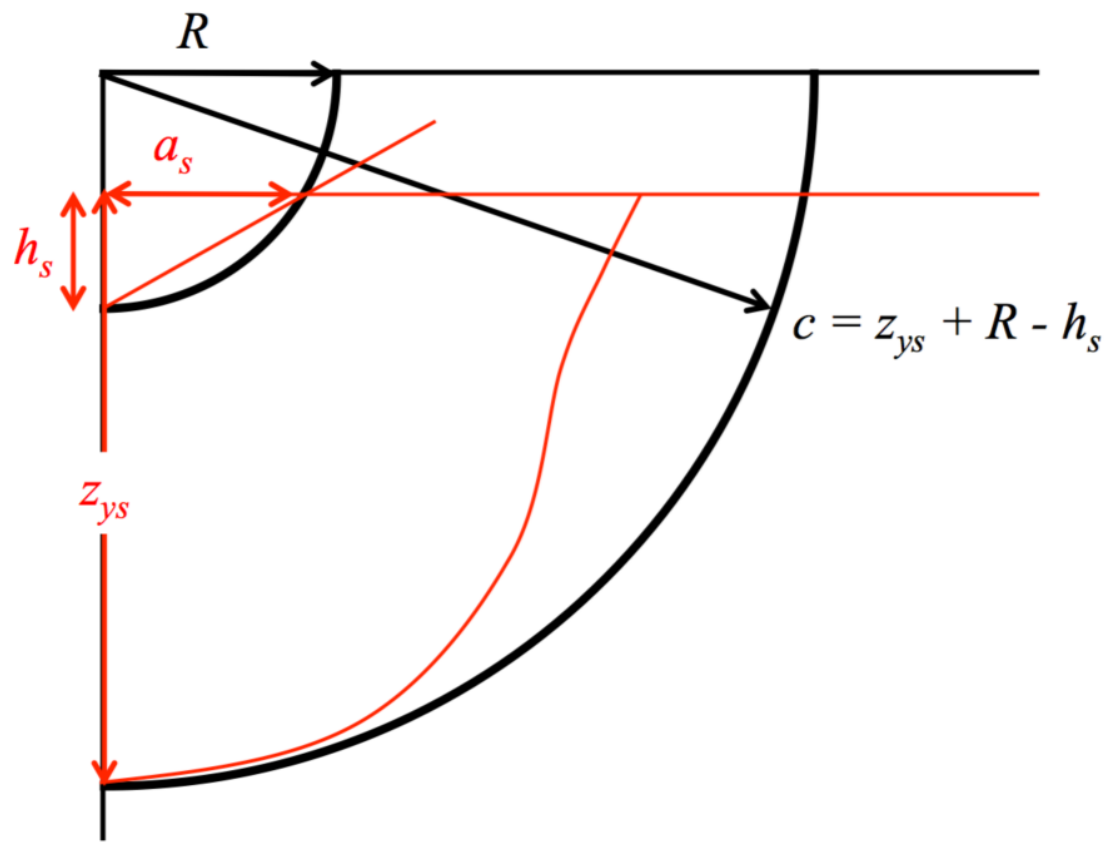

Figure 4. Schematic of spherical cavity model (black) overlaid onto Berkovich geometry (red), after [12]. 


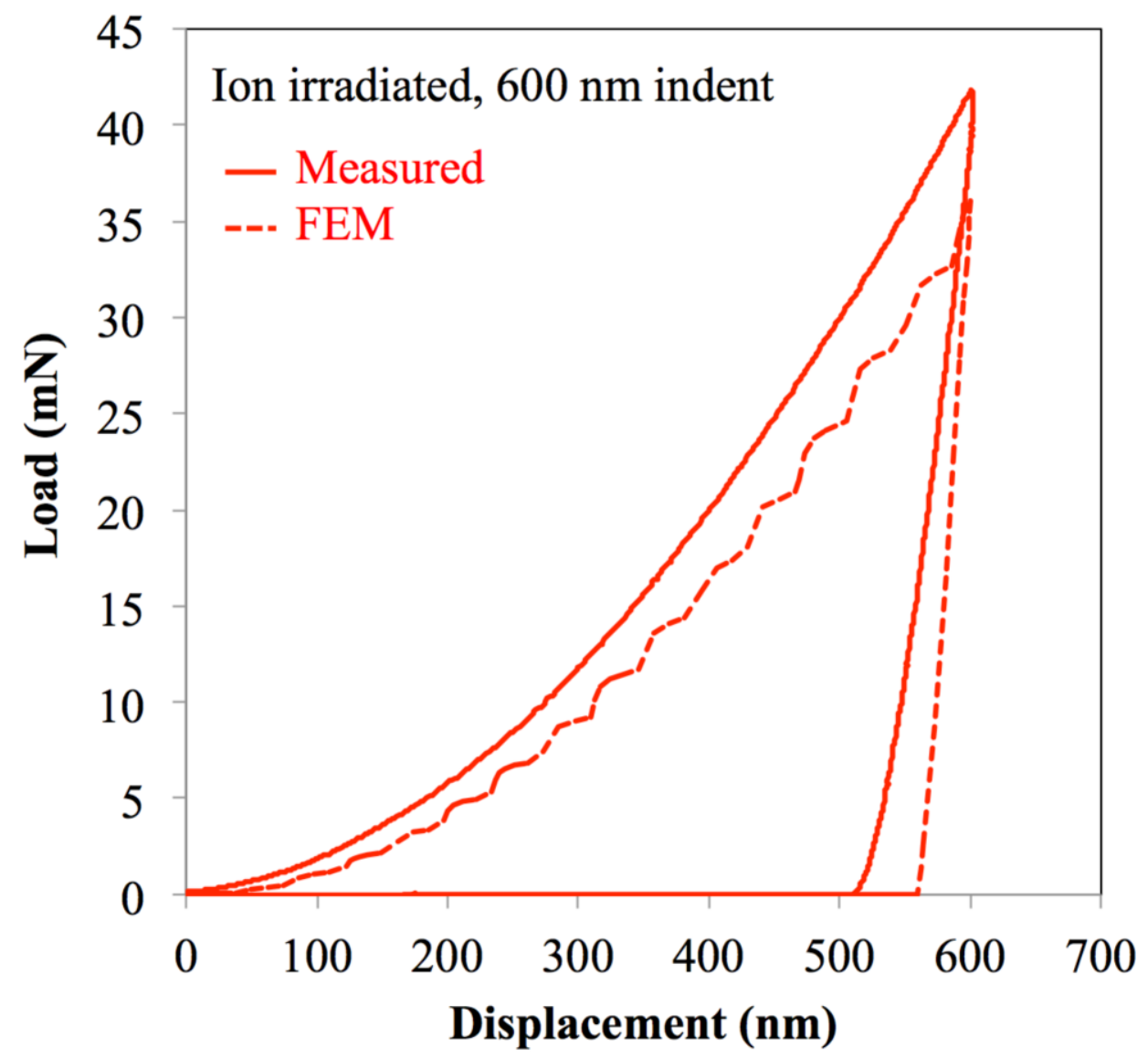

Figure 5. Comparison of load-displacement curves from nanoindentation (solid line) and FEM (dashed line) for $600 \mathrm{~nm}$ indent on the ion-irradiated material. 


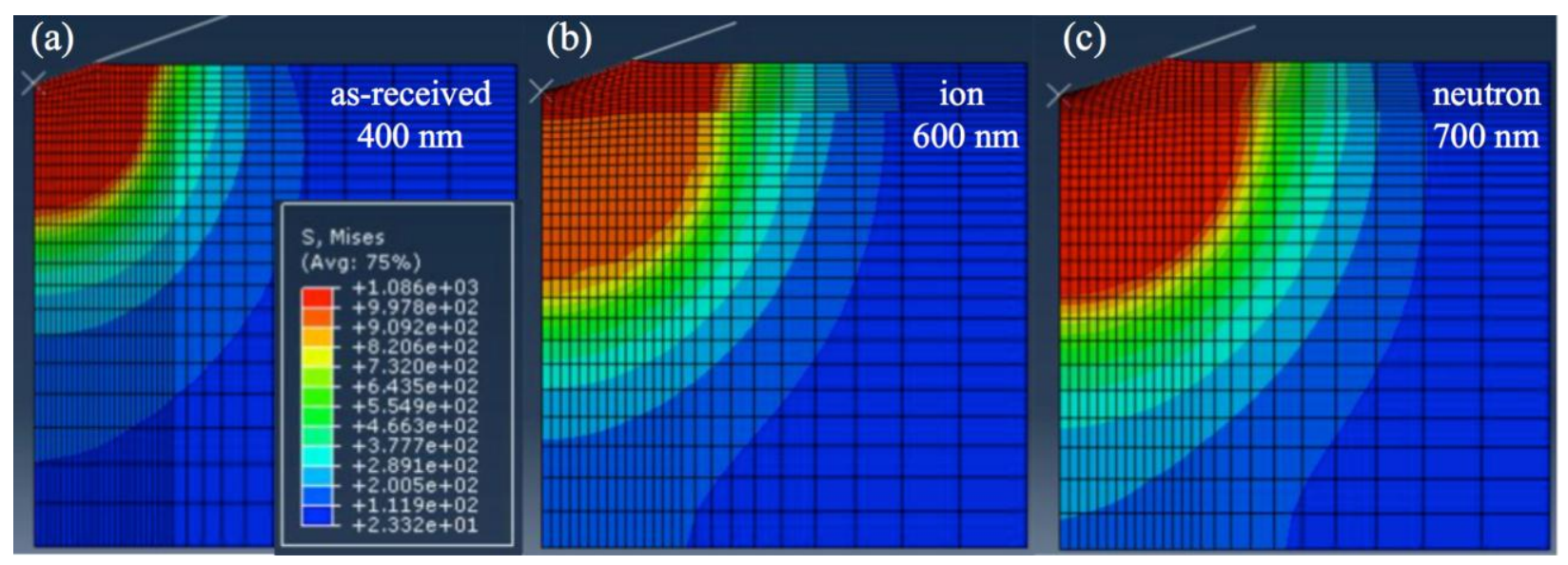

Figure 6. FEM maps of von Mises stress fields under (a) $400 \mathrm{~nm}$ indent in as-received, (b) 600 $\mathrm{nm}$ indent in ion-irradiated, and (c) $700 \mathrm{~nm}$ indent in neutron-irradiated specimens. Regions depicted in red and orange exceed von Mises criteria for plastic flow, and thus represent the plastic zone. Symmetry is assumed across the centerline of the indent and plastic zone. 

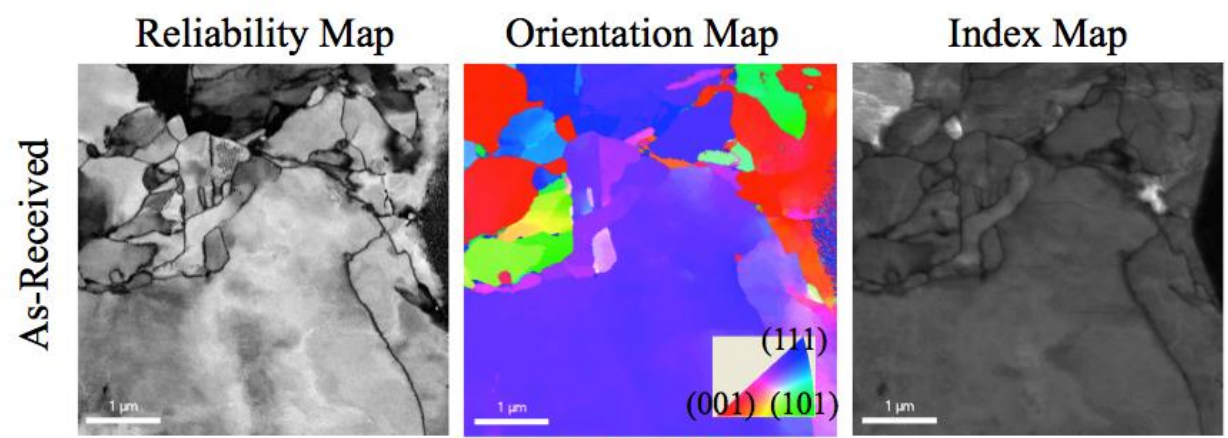

Virtual Bright Field
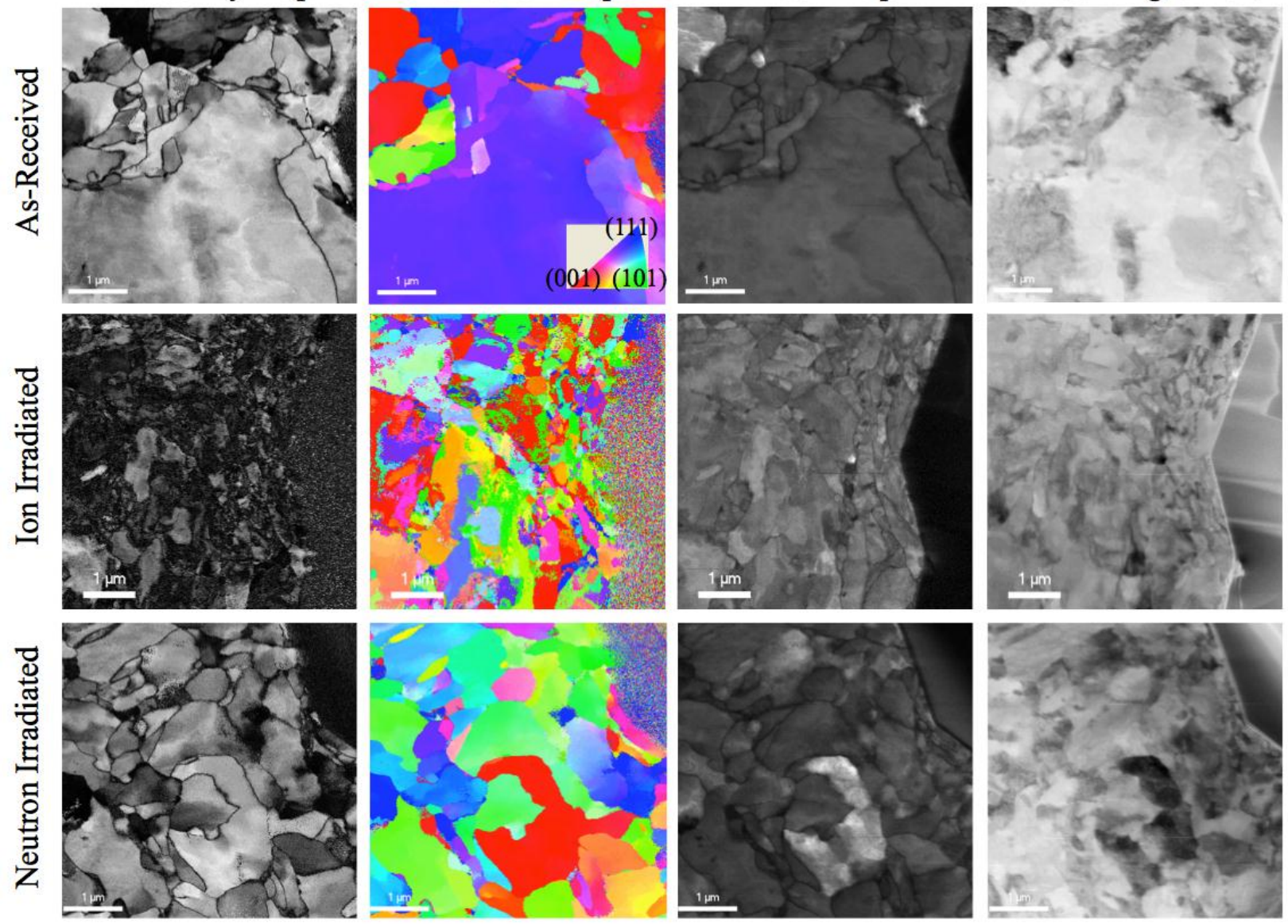

Figure 7. ACOM-TEM images from nanoindent cross-sections for the as-received (top row), ion-irradiated (middle row), and neutron-irradiated (bottom row) specimens. Images shown are reliability maps (leftmost column), orientation maps, index maps, and virtual bright field maps (rightmost column). 


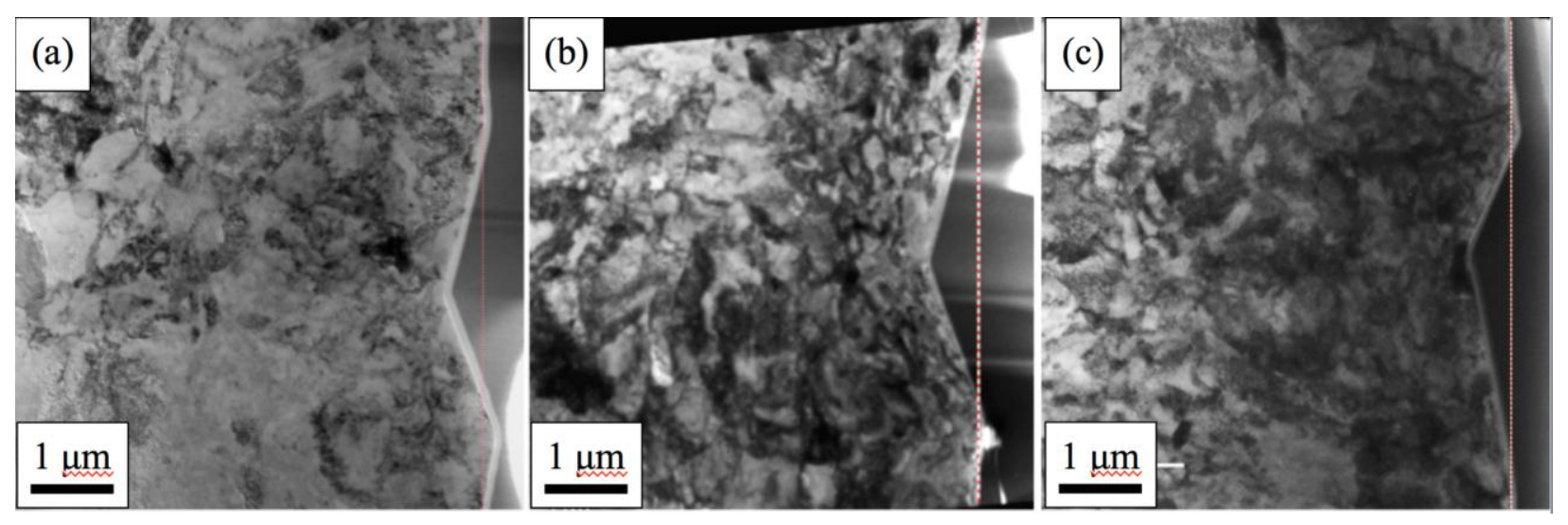

Figure 8. Bright field TEM images of cross-sectional lamellae taken through (a) $400 \mathrm{~nm}$ indent in as-received, (b) $600 \mathrm{~nm}$ indent in ion-irradiated, and (c) $700 \mathrm{~nm}$ indent in neutron-irradiated specimens. Overlaid line indicates original sample surface before nanoindentation. 

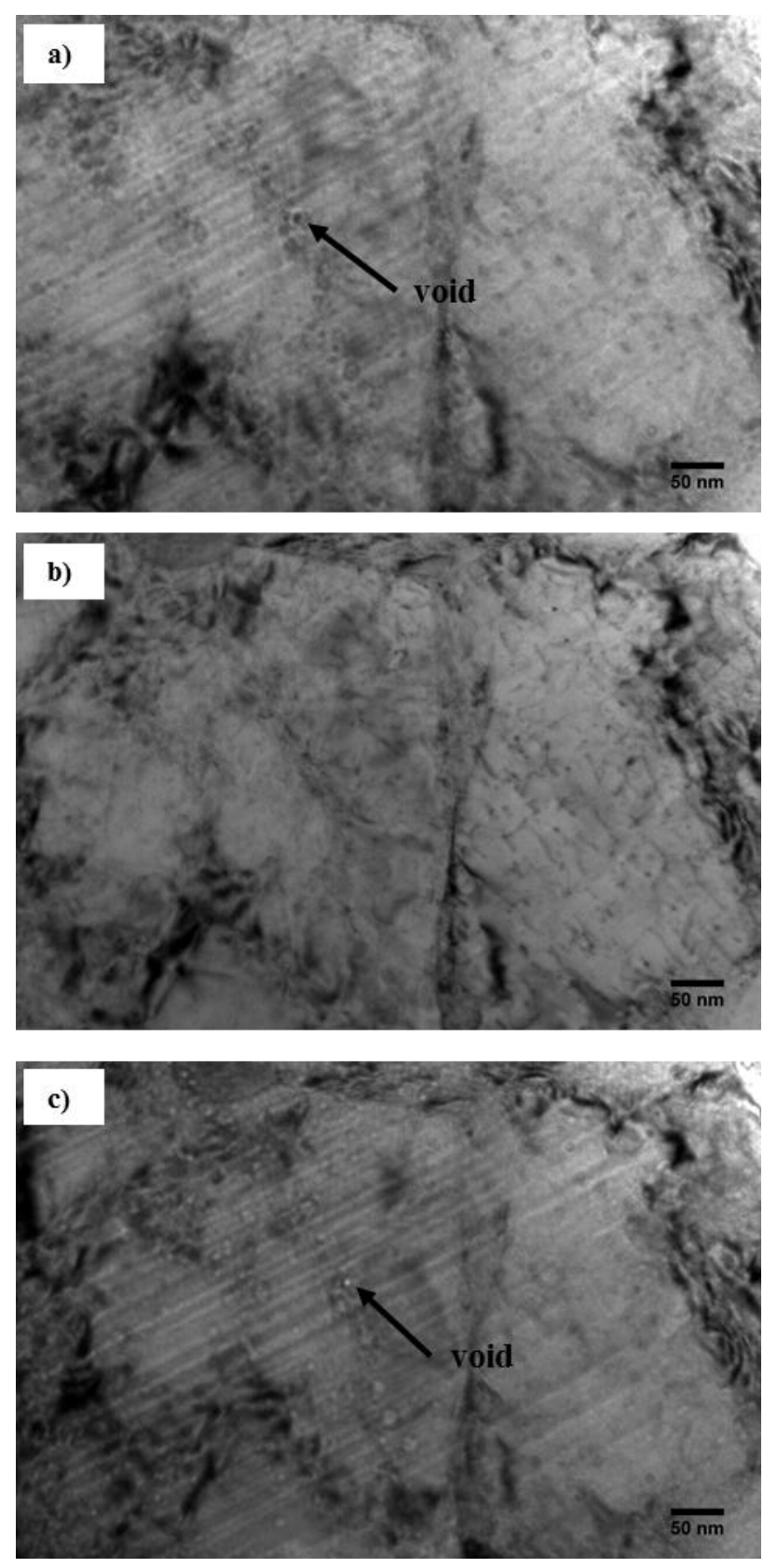

Figure 9. Representative voids in $\mathrm{Fe}-9 \% \mathrm{Cr}$ ODS following $50 \mathrm{dpa}, 400^{\circ} \mathrm{C}$ self-ion irradiation at (a) under-focus, (b) in-focus, and (c) over-focus. 


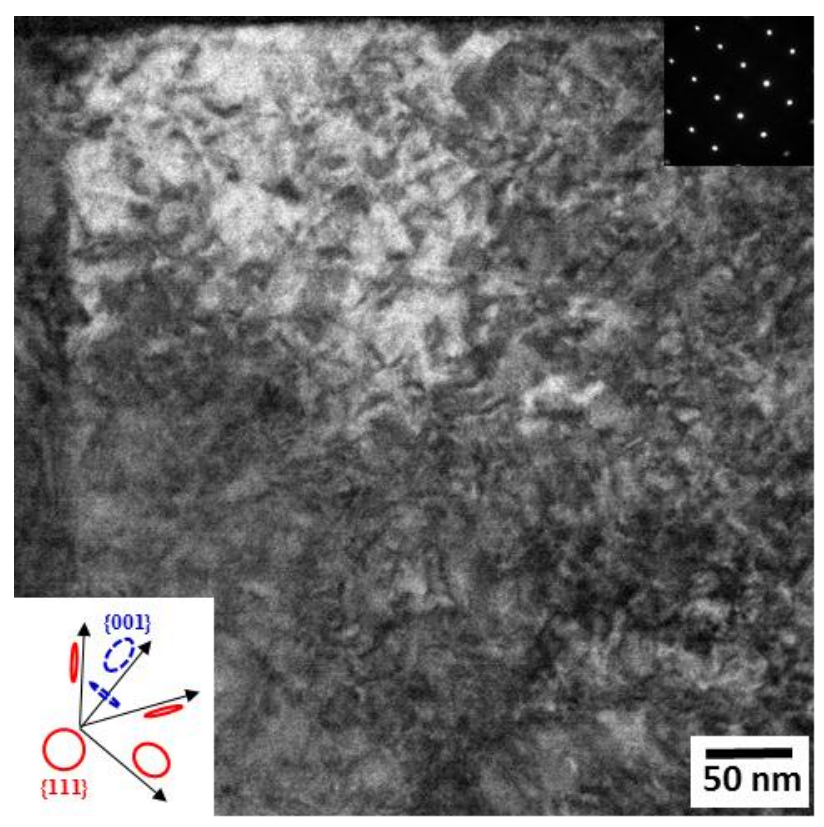

Figure 10. Representative dislocation loops in Fe-9\%Cr ODS imaged along the [011] zone axis after $50 \mathrm{dpa}, 400^{\circ} \mathrm{C}$ self-ion irradiation. 

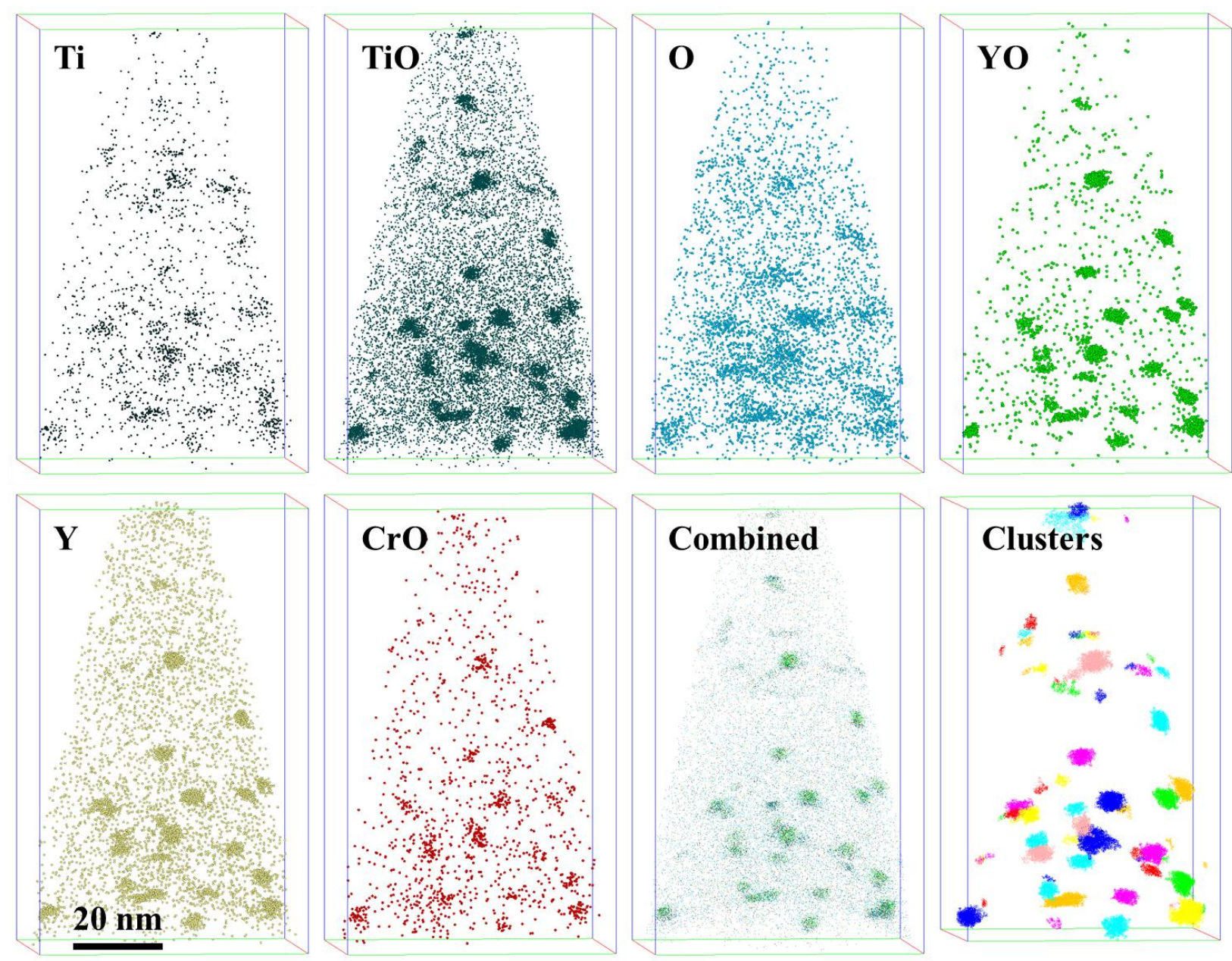

Figure 11. Three-dimensional atom probe reconstructions showing oxide nanoclusters in Fe$9 \% \mathrm{Cr}$ ODS after $50 \mathrm{dpa}, 400^{\circ} \mathrm{C}$ self-ion irradiation. 


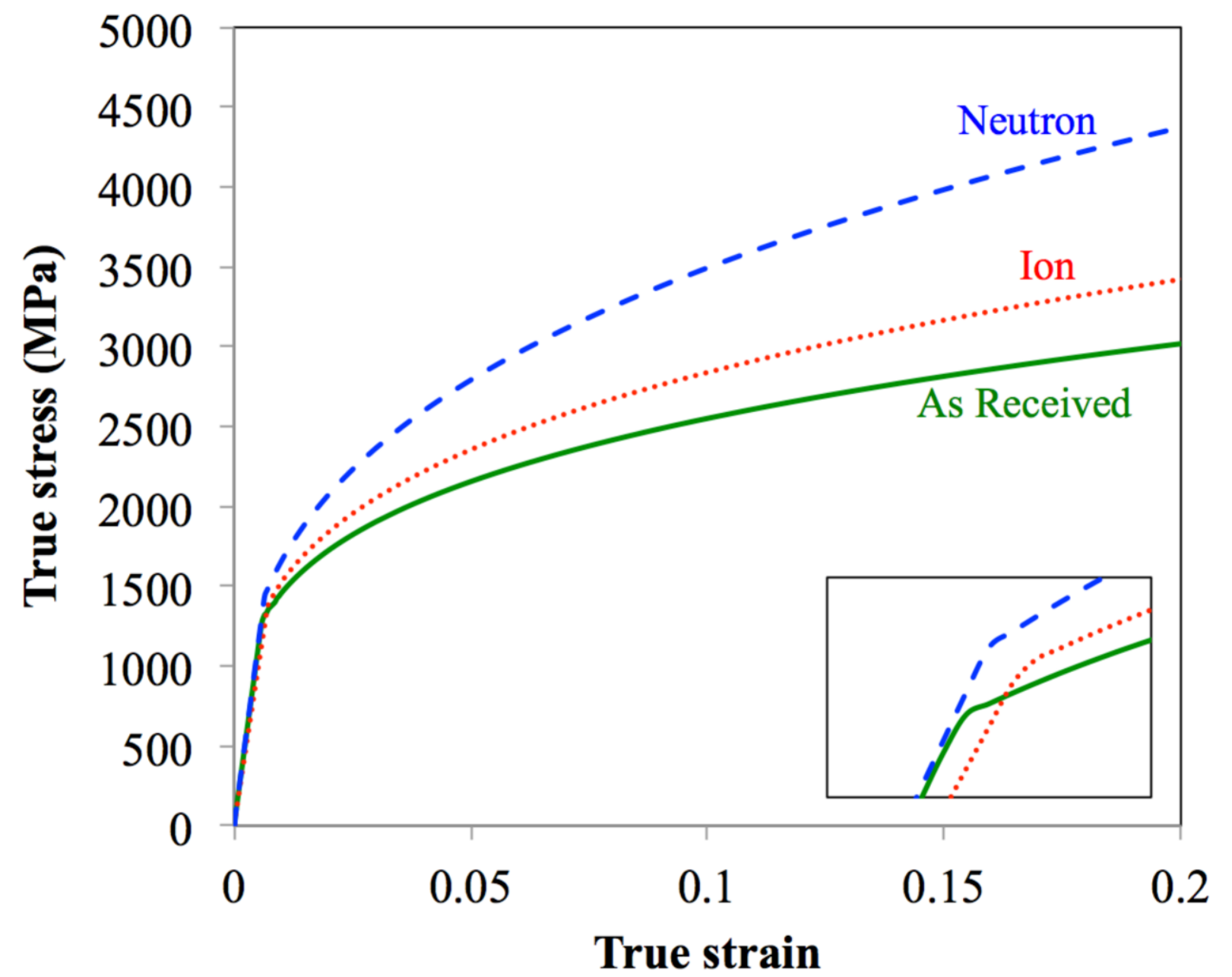

Figure 12. True stress-strain curves reconstructed from nanoindentation for the as-received, ionirradiated, and neutron-irradiated conditions. Inset shows detail of yield points. 


\section{REFERENCES}

[1] D. E. J. Armstrong, C. D. Hardie, J. Gibson, A. J. Bushby, P. D. Edmondson, and S. G. Roberts, "Small-scale characterisation of irradiated nuclear materials: Part II Nanoindentation and micro-cantilever testing of ion irradiated nuclear materials," J. Nucl. Mater., vol. 462, pp. 374-381, 2015.

[2] C. D. Hardie, S. G. Roberts, and A. J. Bushby, "Understanding the effects of ion irradiation using nanoindentation techniques," J. Nucl. Mater., Dec. 2014.

[3] T. Miura, K. Fujii, K. Fukuya, and K. Takashima, "Influence of crystal orientation on hardness and nanoindentation deformation in ion-irradiated stainless steels," J. Nucl. Mater., vol. 417, no. 1-3, pp. 984-987, Oct. 2011.

[4] C. Heintze, F. Bergner, and M. Hernández-Mayoral, "Ion-irradiation-induced damage in $\mathrm{Fe}-\mathrm{Cr}$ alloys characterized by nanoindentation," J. Nucl. Mater., vol. 417, no. 1-3, pp. 980-983, 2011.

[5] N. Li, E. G. Fu, H. Wang, J. J. Carter, L. Shao, S. A. Maloy, A. Misra, and X. Zhang, "He ion irradiation damage in Fe/W nanolayer films," J. Nucl. Mater., vol. 389, no. 2, pp. 233238, 2009.

[6] P. Hosemann, J. G. Swadener, D. Kiener, G. S. Was, S. A. Maloy, and N. Li, “An exploratory study to determine applicability of nano-hardness and micro-compression measurements for yield stress estimation," J. Nucl. Mater., vol. 375, no. 1, pp. 135-143, 2008.

[7] P. M. Rice and R. E. Stoller, "The effect of solutes on defect distributions and hardening in ion-irradiated model ferritic alloys," J. Nucl. Mater., vol. 244, no. 3, pp. 219-226, 1997.

[8] M. D. Gram, J. S. Carpenter, and P. M. Anderson, "An indentation-based method to determine constituent strengths within nanolayered composites," Acta Mater., vol. 92, pp. 255-264, 2015.

[9] D. E. J. Armstrong, A. S. M. A. Haseeb, S. G. Roberts, A. J. Wilkinson, and K. Bade, "Nanoindentation and micro-mechanical fracture toughness of electrodeposited nanocrystalline Ni-W alloy films," Thin Solid Films, vol. 520, no. 13, pp. 4369-4372, 2012.

[10] D. Son, J. Jeong, and D. Kwon, "Film-thickness considerations in microcantilever-beam test in measuring mechanical properties of metal thin film," Thin Solid Films, vol. 437, no. 437, pp. 182-187, 2003.

[11] D. F. Bahr, D. E. Kramer, and W. W. Gerberich, "Non-linear deformation mechanisms during nanoindentation," Acta Mater., vol. 46, no. 10, pp. 3605-3617, 1998.

[12] M. Mata, O. Casals, and J. Alcala, "The plastic zone size in indentation experiments: The analogy with the expansion of a spherical cavity," Int. J. Solids Struct., vol. 43, no. 20, pp. 
5994-6013, 2006.

[13] J. L. Bucaille, S. Stauss, E. Felder, and J. Michler, "Determination of plastic properties of metals by instrumented indentation using different sharp indenters," Acta Mater., vol. 51, no. 6, pp. 1663-1678, 2003.

[14] A. A. Elmustafa and D. S. Stone, "Indentation size effect in polycrystalline F.C.C. metals," Acta Mater., vol. 50, no. 14, pp. 3641-3650, 2002.

[15] A. A. Elmustafa, J. A. Eastman, M. N. Rittner, J. R. Weertman, and D. S. Stone, "Indentation size effect: large grained aluminum versus nanocrystalline aluminumzirconium alloys," Scr. Mater., vol. 43, no. 10, pp. 951-955, 2000.

[16] C. . Woodcock and D. . Bahr, "Plastic zone evolution around small scale indentations," Scr. Mater., vol. 43, no. 9, pp. 783-788, 2000.

[17] D. Kramer, H. Huang, M. Kriese, J. Robach, J. Nelson, A. Wright, D. Bahr, and W. W. Gerberich, "Yield strength predictions from the plastic zone around nanocontacts," Acta Mater., vol. 47, no. 1, pp. 333-343, 1998.

[18] P. Hosemann, D. Kiener, Y. Wang, and S. a. Maloy, "Issues to consider using nano indentation on shallow ion beam irradiated materials," J. Nucl. Mater., vol. 425, no. 1-3, pp. 136-139, Jun. 2012.

[19] W. D. Nix and H. J. Gao, "Indentation size effects in crystalline materials: A law for strain gradient plasticity," J. Mech. Phys. Solids, vol. 46, no. 3, pp. 411-425, 1998.

[20] J. G. Swadener, E. P. George, and G. M. Pharr, "The correlation of the indentation size effect measured with indenters of various shapes," J. Mech. Phys. Solids, vol. 50, no. 4, pp. 681-694, 2002.

[21] Y. Huang, F. Zhang, K. C. Hwang, W. D. Nix, G. M. Pharr, and G. Feng, "A model of size effects in nano-indentation," J. Mech. Phys. Solids, vol. 54, no. 8, pp. 1668-1686, 2006.

[22] C. Robertson, S. Poissonnet, and L. Boulanger, "Plasticity in ion-irradiated austenitic stainless steels," J. Mater. Res., vol. 13, no. 8, pp. 2123-2131, 1997.

[23] S. S. Chiang, D. B. Marshall, and A. G. Evans, "The response of solids to elastic/plastic indentation. I. Stresses and residual stresses,” J. Appl. Phys., vol. 53, no. 1, pp. 298-311, 1982.

[24] E. H. Yoffe, "Elastic Stress Fields Caused by Indenting Brittle Materials," Philos. Mag. A, vol. 46, no. 4, pp. 617-628, 1982.

[25] R. Kasada, S. Konishi, K. Yabuuchi, S. Nogami, M. Ando, D. Hamaguchi, and H. Tanigawa, "Depth-dependent nanoindentation hardness of reduced-activation ferritic steels after MeV Fe-ion irradiation," Fusion Eng. Des., vol. 89, no. 7-8, pp. 1637-1641, 2014. 
[26] R. Kasada, Y. Takayama, K. Yabuuchi, and A. Kimura, "A new approach to evaluate irradiation hardening of ion-irradiated ferritic alloys by nano-indentation techniques," Fusion Eng. Des., vol. 86, no. 9-11, pp. 2658-2661, 2011.

[27] T. Miyazawa, T. Nagasaka, R. Kasada, Y. Hishinuma, T. Muroga, H. Watanabe, T. Yamamoto, S. Nogami, and M. Hatakeyama, "Evaluation of irradiation hardening of ionirradiated V-4Cr-4Ti and V-4Cr-4Ti-0.15Y alloys by nanoindentation techniques," $J$. Nucl. Mater., vol. 455, no. 1-3, pp. 440-444, 2014.

[28] K. L. Johnson, Contact Mechanics. Cambridge, UK: Cambridge University Press, 1985.

[29] M. Mata, M. Anglada, and J. Alcala, "Contact deformation regimes around sharp indentations and the concept of the characteristic strain," J. Mater. Res., vol. 17, no. 5, pp. 964-976, 2002.

[30] Y. Huang, Z. Xue, H. Gao, W. D. Nix, and Z. C. Xia, "A study of microindentation hardness tests by mechanism-based strain gradient plasticity," J. Mater. Res., vol. 15, no. 8, pp. 1786-1796, 2000.

[31] M. Yoshioka, "Plastically deformed region around indentations on Si single crystal," $J$. Appl. Phys., vol. 76, no. 12, pp. 7790-7796, 1994.

[32] H. Li and R. C. Bradt, "Microhardness indentation load/size effect in rutile and cassiterite single crystals," J. Mater. Sci., vol. 28, no. 4, pp. 917-926, 1993.

[33] S. Pasebani, I. Charit, J. Burns, S. F. Alsagabi, D. P. Butt, J. I. J. I. Cole, L. M. Price, and L. Shao, "Microstructural Stability of a Self-Ion Irradiated Lanthana-Bearing Nanostructured Ferritic Steel," J. Nucl. Mater., vol. 462, pp. 191-204, 2015.

[34] M. J. Swenson and J. P. Wharry, "The comparison of microstructure and nanocluster evolution in proton and neutron irradiated $\mathrm{Fe}-9 \% \mathrm{Cr}$ ODs steel to 3 dpa at 500C," J. Nucl. Mater., vol. 467, pp. 97-112, 2015.

[35] A. G. Certain, S. Kuchibhatla, V. Shutthanandan, D. T. Hoelzer, and T. R. Allen, "Radiation stability of nanoclusters in nano-structured oxide dispersion strengthened (ODS) steels," J. Nucl. Mater., vol. 434, no. 1-3, pp. 311-321, 2013.

[36] J. He, F. Wan, K. Sridharan, T. R. Allen, A. G. Certain, V. Shutthanandan, and Y. Q. Wu, "Stability of nanoclusters in 14YWT oxide dispersion strengthened steel under heavy ion irradiation by atom probe tomography," J. Nucl. Mater., vol. 455, no. 1-3, pp. 41-45, 2014.

[37] S. V Rogozhkin, T. V Kulevoy, N. A. Iskandarov, N. N. Orlov, B. B. Chalykh, A. A. Aleev, N. Y. Grachev, R. P. Kujbeda, A. A. Nikitin, and A. D. Fertman, "Simulation experiment on study in the radiation resistance of advanced ferrite-martensite steel hardened by disperse inclusions," At. Energy, vol. 114, no. 1, pp. 14-20, 2013.

[38] A. G. Certain, K. G. Field, T. R. Allen, M. K. Miller, J. Bentley, and J. T. Busby, "Response of nanoclusters in a $9 \mathrm{Cr}$ ODS steel to $1 \mathrm{dpa}, 525^{\circ} \mathrm{C}$ proton irradiation," $\mathrm{J}$. Nucl. Mater., vol. 407, no. 1, pp. 2-9, Dec. 2010. 
[39] H. Kishimoto, R. Kasada, O. Hashitomi, and A. Kimura, "Stability of Y-Ti complex oxides in Fe-16Cr-0.1Ti ODS ferritic steel before and after heavy-ion irradiation," J. Nucl. Mater., vol. 386-388, no. C, pp. 533-536, 2009.

[40] P. Pareige, M. K. Miller, R. E. Stoller, D. T. Hoelzer, E. Cadel, and B. Radiguet, "Stability of nanometer-sized oxide clusters in mechanically-alloyed steel under ioninduced displacement cascade damage conditions," J. Nucl. Mater., vol. 360, no. 2, pp. 136-142, 2007.

[41] J. He, F. Wan, K. Sridharan, T. R. Allen, A. G. Certain, and Y. Q. Wu, "Response of 9CrODS steel to proton irradiation at $400^{\circ} \mathrm{C}$," J. Nucl. Mater., vol. 452, no. 1-3, pp. 87-94, 2014.

[42] M. L. Lescoat, J. Ribis, Y. Chen, E. A. Marquis, E. Bordas, P. Trocellier, Y. Serruys, A. Gentils, O. Kaïtasov, Y. de Carlan, and A. Legris, "Radiation-induced Ostwald ripening in oxide dispersion strengthened ferritic steels irradiated at high ion dose," Acta Mater., vol. 78, pp. 328-340, 2014.

[43] T. R. Allen, J. Gan, J. I. Cole, M. K. Miller, J. T. Busby, S. Shutthanandan, and S. Thevuthasan, "Radiation response of a 9 chromium oxide dispersion strengthened steel to heavy ion irradiation," J. Nucl. Mater., vol. 375, no. 1, pp. 26-37, 2008.

[44] C. Liu, C. Yu, N. Hashimoto, S. Ohnuki, M. Ando, K. Shiba, and S. Jitsukawa, "Microstructure and micro-hardness of ODS steels after ion irradiation," J. Nucl. Mater., vol. 417, no. 1-3, pp. 270-273, Oct. 2011.

[45] C. Robertson, B. K. K. Panigrahi, S. Balaji, S. Kataria, Y. Serruys, M.-H. Mathon, and C. S. Sundar, "Particle stability in model ODS steels irradiated up to $100 \mathrm{dpa}$ at $600^{\circ} \mathrm{C}$ : TEM and nano-indentation investigation," J. Nucl. Mater., vol. 426, no. 1, pp. 240-246, 2012.

[46] I. Monnet, P. Dubuisson, Y. Serruys, M. O. Ruault, O. Kaïtasov, and B. Jouffrey, "Microstructural investigation of the stability under irradiation of oxide dispersion strengthened ferritic steels," J. Nucl. Mater., vol. 335, no. 3, pp. 311-321, 2004.

[47] M. J. Swenson, C. K. Dolph, and J. P. Wharry, "The effects of oxide evolution on mechanical properties in irradiated Fe-9\%Cr ODS," J. Nucl. Mater. Submitt. Manuscr.

[48] R. E. Stoller, M. B. Toloczko, G. S. Was, A. G. Certain, S. Dwaraknath, and F. A. Garner, "On the use of SRIM for computing radiation damage exposure," Nucl. Instruments Methods Phys. Res. Sect. B Beam Interact. with Mater. Atoms, vol. 310, pp. 75-80, 2013.

[49] J. F. Ziegler, "The Stopping and Range of Ions in Matter (SRIM)," 2013.

[50] G. S. Was, Fundamentals of Radiation Materials Science: Metals and Alloys. Springer, 2007.

[51] K. L. Murty and I. Charit, An Introduction to Nuclear Materials: Fundamentals and Applications. Singapore: Wiley-VCH, 2013.

[52] W. C. Oliver and G. M. Pharr, "Measurement of hardness and elastic modulus by 
instrumented indentation: Advances in understanding and refinements to methodology," $J$. Mater. Res., vol. 19, no. 1, pp. 3-20, 2004.

[53] A. C. Fischer-Cripps, Nanoindentation. New York: Springer, 2011.

[54] P. Hosemann, E. Stergar, L. Peng, Y. Dai, S. A. Maloy, M. A. Pouchon, K. Shiba, D. Hamaguchi, and H. Leitner, "Macro and microscale mechanical testing and local electrode atom probe measurements of STIP irradiated $\mathrm{F} 82 \mathrm{H}, \mathrm{Fe}-8 \mathrm{Cr}$ ODS and $\mathrm{Fe}-8 \mathrm{Cr}-2 \mathrm{~W}$ ODS," J. Nucl. Mater., vol. 417, no. 1-3, pp. 274-278, Oct. 2011.

[55] L. A. Giannuzzi and F. A. Stevie, Introduction to focused ion beams : instrumentation, theory, techniques, and practice. New York: Springer, 2005.

[56] K. Thompson, D. Lawrence, D. J. Larson, J. D. Olson, T. F. Kelly, and B. Gorman, "In situ site-specific specimen preparation for atom probe tomography," Ultramicroscopy, vol. 107, no. 2, pp. 131-139, 2007.

[57] C. M. Parish, K. G. Field, A. G. Certain, and J. P. Wharry, "Application of STEM characterization for investigating radiation effects in BCC Fe-based alloys," J. Mater. Res., vol. 30, p. In Press, 2015.

[58] E. F. Rauch and M. Véron, "Automated Crystal Orientation and Phase Mapping in TEM," Mater. Charact., vol. 98, pp. 1-9, 2014.

[59] D. Kiener, R. Pippan, C. Motz, and H. Kreuzer, "Microstructural evolution of the deformed volume beneath microindents in tungsten and copper," Acta Mater., vol. 54, no. 10, pp. 2801-2811, 2006.

[60] C. Robertson and M. C. Fivel, "A study of the submicron indent-induced plastic deformation,” J. Mater. Res., vol. 14, no. 6, pp. 2251-2258, 1996.

[61] TI 950 TriboIndenter User Manual, 9.3.0314 ed. Hysitron, 2014.

[62] R. F. Bishop, R. Hill, and F. R. S. Mott, "The theory of indentation and hardness tests," Proc. Phys. Soc., vol. 57, pp. 147-159, 1945.

[63] K. L. Johnson, “The correlation of indentation experiments," J. Mech. Phys. Solids, vol. 18 , pp. $115-126,1970$.

[64] R. Hill, The Mathematical Theory of Plasticity. Oxford, UK: Oxford University Press, 1950.

[65] S. H. Chen, L. Liu, and T. C. Wang, "Small scale, grain size and substrate effects in nanoindentation experiment of film-substrate systems," Int. J. Solids Struct., vol. 44, no. 13, pp. 4492-4504, 2007.

[66] B. Bose and R. J. Klassen, "Effect of ion irradiation and indentation depth on the kinetics of deformation during micro-indentation of $\mathrm{Zr}-2.5 \% \mathrm{Nb}$ pressure tube material at 25 ??C," J. Nucl. Mater., vol. 399, no. 1, pp. 32-37, 2010.

[67] B. Yao, D. J. Edwards, and R. J. Kurtz, "TEM characterization of dislocation loops in 
irradiated bcc Fe-based steels," J. Nucl. Mater., vol. 434, no. 1-3, pp. 402-410, Mar. 2013.

[68] D. Tabor, Hardness of Metals. United Kingdom: Clarendon Press, 1951.

[69] Y. Wu, J. Ciston, S. Kräemer, N. Bailey, G. R. Odette, and P. Hosemann, “The crystal structure, orientation relationships and interfaces of the nanoscale oxides in nanostructured ferritic alloys," Acta Mater., vol. 111, pp. 108-115, 2016.

[70] C. Robertson and K. Gururaj, "Plastic deformation of ferritic grains in presence of ODS particles and irradiation-induced defect clusters: A 3D dislocation dynamics simulation study," J. Nucl. Mater., vol. 415, no. 2, pp. 167-178, 2011. 